\title{
Marine ammonia-oxidising archaea and bacteria occupy distinct iron and copper niches
}

\author{
Roxana T. Shafiee ${ }^{1}{ }^{1}$, Poppy J. Diver ${ }^{1}{ }^{1}$, Joseph T. Snow ${ }^{1}$, Qiong Zhang ${ }^{1}{ }^{1}$ and Rosalind E. M. Rickaby ${ }^{1}$ \\ (c) The Author(s) 2021
}

Ammonia oxidation by archaea and bacteria ( $A O A$ and $A O B$ ), is the first step of nitrification in the oceans. As $A O A$ have an ammonium affinity 200 -fold higher than $A O B$ isolates, the chemical niche allowing $A O B$ to persist in the oligotrophic ocean remains unclear. Here we show that marine isolates, Nitrosopumilus maritimus strain SCM1 (AOA) and Nitrosococcus oceani strain C-107 (AOB) have contrasting physiologies in response to the trace metals iron (Fe) and copper ( $\mathrm{Cu}$ ), holding potential implications for their niche separation in the oceans. A greater affinity for unchelated Fe may allow AOB to inhabit shallower, euphotic waters where ammonium supply is high, but competition for Fe is rife. In contrast to AOB, AOA isolates have a greater affinity and toxicity threshold for unchelated $\mathrm{Cu}$ providing additional explanation to the greater success of $\mathrm{AOA}$ in the marine environment where $\mathrm{Cu}$ availability can be highly variable. Using comparative genomics, we predict that the proteomic and metal transport basis giving rise to contrasting physiologies in isolates is widespread across phylogenetically diverse marine AOA and AOB that are not yet available in pure culture. Our results develop the testable hypothesis that ammonia oxidation may be limited by $\mathrm{Cu}$ in large tracts of the open ocean and suggest a relatively earlier emergence of $A O B$ than $A O A$ when considered in the context of evolving trace metal availabilities over geologic time.

ISME Communications (2021)1:1 ; https://doi.org/10.1038/s43705-021-00001-7

\section{INTRODUCTION}

Ammonia-oxidising archaea $(\mathrm{AOA})$ and bacteria $(\mathrm{AOB})$ mediate the first step of nitrification, the stepwise oxidation of ammonium $\left(\mathrm{NH}_{4}{ }^{+}\right)$to nitrite $\left(\mathrm{NO}_{2}{ }^{-}\right)$and nitrate $\left(\mathrm{NO}_{3}{ }^{-}\right)$- the central component of biogeochemical nitrogen cycling. A third group of aerobic ammonia oxidisers has also been identified, mediating complete aerobic ammonia oxidation to nitrate (comammox). ${ }^{1}$ AOA widely outnumber their bacterial counterparts in a range of environments including soils, ${ }^{2}$ freshwater streams and lakes ${ }^{3-5}$ and the marine environment. ${ }^{6-12}$ In the oligotrophic open ocean, archaeal $a m o A$ genes, an indicator of cell abundance, are up to three orders of magnitude greater than those of $A O B,{ }^{7,10-13}$ hypothesised to be due to the greater affinity of AOA for their shared substrate $\mathrm{NH}_{4}+{ }^{+14}$ Yet $\mathrm{NH}_{4}{ }^{+}$growth kinetics are unable to solely account for the dominance of $A O A$ in some coastal, estuarine and openocean environments ${ }^{15-17}$ where $\mathrm{NH}_{4}^{+}$supply is enough to support AOB growth, indicating that additional adaptive mechanisms contribute to the greater success of AOA. Further, the coexistence of $A O B$ with $A O A$ in marine environments albeit at low abundances of $A O B,{ }^{6-13}$ suggests that $A O B$ occupy a distinct chemical niche allowing them to persist despite a low affinity for $\mathrm{NH}_{4}^{+}{ }^{+14}$

The genome sequence of the marine AOA isolate, Nitrosopumilus maritimus SCM1 revealed the presence of numerous copperrich halo- and plastocyanin enzymes ${ }^{18}$ in lieu of Fe-dense cytochromes typically found in $\mathrm{AOB}^{19,20}$ alluding to a potential role for trace metals in the niche separation between AOA and AOB. Subsequent studies ${ }^{21,22}$ have revealed that the cupric ion $\left(\mathrm{Cu}^{2+}\right)$ and unchelated Fe (Fe') requirement for optimal growth in
N. maritimus ( $1 \mathrm{pmol} \mathrm{L}^{-1} \mathrm{Cu}^{2+}$ and $550 \mathrm{pmol} \mathrm{L}^{-1} \mathrm{Fe}^{\prime}$ ) are above those typically measured in the marine environment $(\sim 0.01-0.1$ pmol L ${ }^{-1} \mathrm{Cu}^{2+}$ and $\sim 1 \mathrm{pmol} \mathrm{L}^{-1} \mathrm{Fe}$ ), presenting the potential for marine nitrification to be limited by these metals in the open oceans. Growth limitation by $\mathrm{Fe}$ or $\mathrm{Cu}$ is welldocumented in other components of the marine $\mathrm{N}$-cycle including nitrogen fixation, ${ }^{23,24}$ $\mathrm{NO}_{3}{ }^{-}$assimilation ${ }^{25}$ and denitrification. ${ }^{26}$ There has yet to be an equivalent physiological analysis of marine $A O B \mathrm{Fe}$ and $\mathrm{Cu}$ requirements for growth, precluding an accurate assessment of the role of these metals in modulating marine ammonia oxidation rates and shaping the niche separation between $A O A$ and $A O B$. Comparison of $\mathrm{Fe}$ and $\mathrm{Cu}$ requirements also provides a new perspective on the longstanding question of $A O A$ and $A O B$ relative emergence, drawing on the idea that extant microorganisms contain imprints of shifting trace metal bioavailabilities over geologic time at the cellular level. ${ }^{27-30}$

Here, we provide the first physiological examination of the trace metal requirements of any marine $\mathrm{AOB}$ isolate, reporting the free inorganic Fe and $\mathrm{Cu}$ requirements of Nitrosococcus oceani strain C107 (ATCC 19707). N. oceani belongs to the $\gamma$-subdivision of the Proteobacteria, an omnipresent $A O B$ group in seawater. ${ }^{31,32}$ We compare the physiological response of $N$. oceani to unchelated Fe and $\mathrm{Cu}$ availability with that of the cultured marine AOA isolate, Nitrosopumilus maritimus strain SCM1 from previous work ${ }^{21,22}$ supplementing the published data with the intracellular Cu quota of $N$. maritimus SCM1. To explore whether the physiologies and uptake strategies of $N$. oceani C-107 and N. maritimus SCM1 reflect broader marine $A O A$ and $A O B$ communities, pure isolates for

${ }^{1}$ Department of Earth Sciences, University of Oxford, Oxfordshire, UK. ${ }^{\circledR}$ email: roxana.shafiee@earth.ox.ac.uk 
which are not yet available, we perform a two-pronged bioinformatic analysis of the metal-binding sites and metal transporter systems in $\mathrm{AOA}$ and $\mathrm{AOB}$ genomes.

\section{METHODS \\ Nitrosococcus oceani C-107 cultures and growth media}

Polycarbonate culture vessels and culturing apparatus were acid-cleaned in $10 \%$ (v/v) TraceMeta ${ }^{\mathrm{TM}}$ grade HCl (Fisher Scientific, Loughborough, UK) for 24 $\mathrm{h}$ and UV-sterilised before use. Triplicate $10 \mathrm{ml}$ cultures of Nitrosococcus oceani strain C-107 (ATCC 19707 originally isolated from the open North Atlantic) herein referred to as $\mathrm{N}$. oceani, were grown in modified SCM medium ${ }^{33}$ amended with additional $\mathrm{NH}_{4} \mathrm{Cl}$ (final $\mathrm{NH}_{4}^{+}$concentration $10 \mathrm{mM}$ ) and maintained at $30^{\circ} \mathrm{C}$ in the dark on a rotary shaker (150 r.p.m.). Basal salt medium and macronutrients were treated with Chelex-100 resin (BioRad, Watford, UK) to remove trace metal contaminants ${ }^{34}$ and passed through an acid-washed $(10 \% \mathrm{HCl}$ as before) $0.2 \mu \mathrm{m}$ polycarbonate filter to sterilise in a metal-free clean laboratory. The final $\mathrm{pH}$ of the media was 7.5 and was buffered with HEPES. To investigate the effect of unchelated inorganic $\mathrm{Fe}$ $\left(\mathrm{Fe} \mathrm{e}^{\prime}\right)$ and copper $\left(\mathrm{Cu}^{\prime}\right)$ concentrations on $\mathrm{N}$. oceani growth, ethylenediaminetetraacetic acid (EDTA, Merck, Darmstadt, Germany) was used to buffer Fe, $\mathrm{Cu}$ and other metals in cultures. Fe' and $\mathrm{Cu}^{\prime}$ were controlled by varying the addition of $\mathrm{FeCl}_{3}$ or $\mathrm{CuCl}_{2}$ from filter-sterilised concentrated stocks made using $>99.999 \%$ trace metal basis salts (Sigma Aldrich, UK) and maintaining a constant concentration of EDTA at $25 \mu \mathrm{mol} \mathrm{L}^{-1}$ (Fe experiments) or $120 \mu \mathrm{mol}$ $\mathrm{L}^{-1}$ (Cu experiments)-EDTA concentrations which have been shown to be non-toxic to Nitrosococcus in previous work. ${ }^{35,36} \mathrm{Fe}^{\prime}, \mathrm{Cu}^{\prime}$ and cupric ion $\left(\mathrm{Cu}^{2+}\right)$ concentrations were calculated using Visual Minteq software. ${ }^{37} \mathrm{Cu}^{2+}$ is presented in main figures, in order to allow for comparison with previous $\mathrm{Cu}$ growth experiments of $\mathrm{AOA}$ and phytoplankton $\mathrm{Cu}$ studies and measurements made in the field, which use $\mathrm{Cu}^{2+}$. $\mathrm{Cu}^{\prime}$ values are given in Table 1 and Supplementary Fig. 1. Background Fe and Cu blank levels of 1.4 and $12.5 \mathrm{nmol} \mathrm{L}^{-1}$, respectively, from basal SCM medium, were measured using inductively-coupled plasma mass spectrometry $(\text { ICP-MS })^{38}$ and included in the calculation of metal speciation. Cultures were acclimated to $\mathrm{Fe}^{\prime}$ and $\mathrm{Cu}^{\prime} / \mathrm{Cu}^{2+}$ by transferring cultures consecutively during the late exponential growth phase into new media until growth rates did not vary with statistical significance (ANOVA, $P<0.05$ ). The growth rate was determined by measuring nitrite $\left(\mathrm{NO}_{2}^{-}\right)$spectrophotometrically over time as in previous studies (Supplementary Fig. $2^{33,39-41}$ ), the production of which correlates with cell counts. ${ }^{22,23}$ Specific growth rate $\left(\mathrm{d}^{-1}\right)$ was calculated over the linear phase of semi-log plots of nitrite $\left(\mathrm{NO}_{2}{ }^{-}\right)$concentration over time.

\section{Nitrosopumilus maritimus SCM1 cultures}

To supplement previously published data with the intracellular Cu quota of Nitrosopumilus maritimus strain SCM1 (herein referred to as N. maritimus) N. maritimus cultures were maintained as previously described. ${ }^{22}$ In brief, triplicate cultures of $N$. maritimus were grown in SCM media ${ }^{33}$ treated with Chelex-100 resin, with $1 \mathrm{mM} \mathrm{NH}_{4} \mathrm{Cl}$ (final concentration) and maintained in the dark at $28^{\circ} \mathrm{C}$. Cultures were acclimated to optimal $\mathrm{Cu}^{2+}$ concentrations $\left(1 \mathrm{pmol} \mathrm{L^{-1 }} \mathrm{Cu}^{2+}\right)$ determined in a previous study. ${ }^{22}$ Full details of $N$. maritimus culturing method are provided in Supplementary Materials.

\section{Trace metal quota analysis of cells}

All samples and reagents were processed using trace metal clean techniques and acid-washed plastic wear in a clean laboratory before trace element analysis. $N$. oceani and $N$. maritimus cells at $\mu_{\max }$ (see Supplementary Materials for full discussion of $\mathrm{Fe}^{\prime}$ and $\mathrm{Cu}^{2+}$ chosen for trace metal analysis) were harvested in mid-exponential phase by centrifugation at $5000 \times \mathrm{g}$ for $25 \mathrm{~min}$ and then rinsed three times with Chelex-100-treated SCM media to remove weakly bound surface metals. ${ }^{38}$ Cells were digested in acid-cleaned Teflon as follows: refluxing at $100^{\circ} \mathrm{C}$ with $16 \mathrm{~N}$ quartz-distilled (q.d.) $\mathrm{HNO}_{3}$ (produced in-house) and $\mathrm{H}_{2} \mathrm{O}_{2}$ (ROMIL $\mathrm{UpA}^{\mathrm{TM}}$, Cambridge, UK) in a ratio of $3: 2$ overnight. The liquid was then allowed to evaporate to dryness and $2 \%$ q.d. $\mathrm{HNO}_{3}$ was added to reflux for an hour to resuspend the dried samples. ${ }^{56} \mathrm{Fe},{ }^{31} \mathrm{P}$ and ${ }^{63} \mathrm{Cu}$ concentrations were determined using a Quadrupole ICP-MS Perkin Elmer NexION 350 with Elemental Scientific Flow Injection Auto-sampler (FIAS) in a method optimised for high-salt matrices. ${ }^{38}$

\section{Steady-state iron uptake rate}

The steady-state $\mathrm{Fe}^{\prime}$ uptake rate, $\rho_{s s}$ the product of intracellular Fe quota $\left(\mathrm{mol} \mathrm{cell}{ }^{-1}\right)$ and specific growth rate $\left(\mathrm{hr}^{-1}\right)$ and steady-state uptake constant, $K_{i n}, \rho_{s s}$ normalised to $\mathrm{Fe}^{\prime}$ in the medium, were calculated for $N$. oceani as per previous work ${ }^{22,42}$ using Fe-limited cellular quotas (Table 1). Cellular quotas measured in $\mathrm{N}$. oceani cells cultured at $100 \mathrm{pmol} \mathrm{L}^{-1} \mathrm{Fe}^{\prime}$ $\left(66 \%\right.$ of $\left.\mu_{\max }\right)$ and $376 \mathrm{pmol} \mathrm{L^{-1 }} \mathrm{Fe}^{\prime}\left(78 \%\right.$ of $\left.\mu_{\max }\right)$ were used in calculations. To obtain a steady-state uptake constant per unit surface area (S.A.), S.A. was calculated based on a spherical cell shape and using a radius of $1 \mu \mathrm{m}$ obtained from SEM imaging (Supplementary Fig. 3), preparing cells using the same protocol as in ref. ${ }^{23}$, which is fully outlined in Supplementary Materials.

\section{FeDFB and ferrozine experiments}

To examine whether $N$. oceani can utilise organically chelated $\mathrm{Fe}, N$. oceani was cultured in medium with the addition of the siderophore desferrioxamine B mesylate (DFB, Merck) to buffer Fe. N. oceani was cultured under high and low concentrations of total dissolved $\mathrm{Fe}, \mathrm{dFe}$, corresponding to

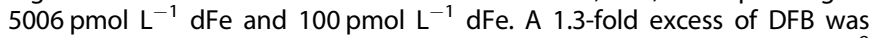
added over $\mathrm{Fe}$, in order to reduce $\mathrm{Fe}^{\prime}$ to negligible concentrations $\left(<1 \times 10^{9}\right.$ pmol L $\left.\mathrm{L}^{-1} \mathrm{Fe}^{\prime}\right)$. EDTA was added in a low concentration ( $12 \mu \mathrm{mol} \mathrm{L}^{-1}$ EDTA) to buffer other trace metals. We used the ferrozine assay ${ }^{42}$ to identify whether $N$. oceani adopts a reductive Fe uptake pathway in Fe acquisition. Ferrozine (FZ, 5,6-diphenyl-3-(2-pyridyl)-1,2,4-triazine) binds with any available $\mathrm{Fe}^{2+}$ in the medium forming a $\mathrm{Fe}(\mathrm{II})-\mathrm{FZ}_{3}$ complex which is unavailable for uptake across the outer cell membrane. ${ }^{43}$ Inhibition of growth with the addition of FZ therefore indicates that cells are actively reducing $\mathrm{Fe}^{3+}$ to $\mathrm{Fe}^{2+}$ during $\mathrm{Fe}$ acquisition. $N$. oceani cultures were acclimated to replete and deplete $\mathrm{Fe}^{\prime}\left(5006 \mathrm{pmol} \mathrm{L}^{-1} \mathrm{Fe}^{\prime}\right.$ and $100 \mathrm{pmol} \mathrm{L}^{-1}$ $\left.\mathrm{Fe}^{\prime}\right)$, then transferred to new media with $200 \mu \mathrm{mol} \mathrm{L}^{-1} \mathrm{FZ}$. Growth rate $(\mu)$ was determined as previously outlined.

\section{Bioinformatic predictions of AOA and AOB physiology in wider communities}

The limited number of marine $A O A$ and $A O B$ species isolated into pure culture precludes an extensive physiological analysis of the trace metal requirements across the wider $\mathrm{AOA} / \mathrm{AOB}$ community using culture-based approaches. To explore whether the physiologies of N. oceani C-107 and N. maritimus SCM1 may reflect broader marine $A O A$ and $A O B$ communities, we used available genome-predicted proteomes (downloaded from UniProt: https://www.uniprot.org) to annotate the hypothetical Cu- and Fe-binding sites in marine $A O A$ and $A O B$, on the basis that physiological requirement typically scales with the number of metal-binding sites. In addition, we annotated the presence of metal transporter systems to explore whether the genetic basis for the contrasting metal affinities of $N$. oceani and $N$. maritimus in culture is ubiquitous among the broader AOA and $\mathrm{AOB}$ community.

For both analyses, only genome-predicted proteomes with a high genome completeness $(>96 \%)$ were used (full search criteria outlined in Supplementary Materials). For annotation of $\mathrm{Cu}$ and Fe binding sites, protein sequences were submitted to the PHYRE2 protein fold recognition server to identify homologues for known protein structures. ${ }^{43}$ Significant matches ( $>95 \%$ confidence) were submitted to metalPDB ${ }^{44}$ which models the 3D minimal functional sites (MFSs) surrounding metals. Metals were assigned if the search returned significant sequence similarity to metalbinding sites in other proteins $\left(E\right.$-value $\left.<10^{-5}\right)$. To confirm that genomepredicted proteomes were reflective of expressed proteome metal demands, we performed the same analyses with available published expressed proteomes (Supplementary Figs. 4 and 5). We used both marine and coastal $A O A$ and $A O B$ in our analyses as they were shown to be statistically indistinguishable in terms of genome-predicted proteome metal demand (see Supplementary Fig. 6 and Supplementary Methods for further clarification).

To annotate metal transporter families, we adopted an approach similar to previous studies ${ }^{45}$ where conserved domains were identified using the NCBI-conserved domains database ${ }^{46}$ and were then searched against currently characterised metal transport systems (full list in Supplementary Material). Orthologues were identified using a BLAST search ( $E$-value $<10^{-5}$ ). Each presence of a transporter family gene was considered as a 'count' and count numbers were plotted against species. Genomes and transporter families included in this analysis are discussed in greater detail in the Supplementary Material.

\section{Data analysis}

All statistical analyses were performed using Minitab v.13.1. Data were examined for normality and equal variance prior to Student's $T$ test, 


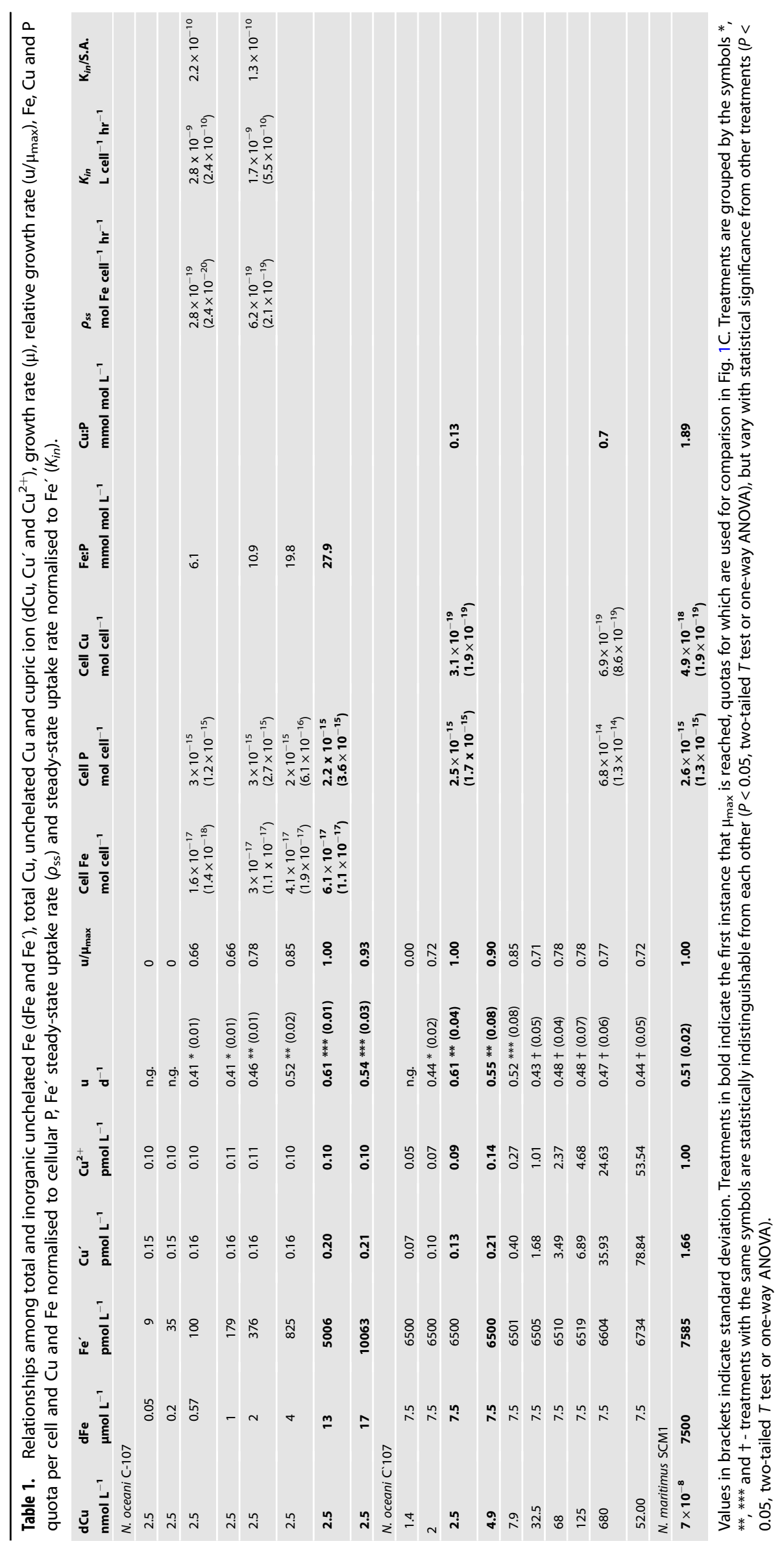


analysis of variance (ANOVA) or Mann-Whitney $U$ statistical tests. Significant results are reported at the $95 \%$ confidence level $(P<0.05)$ unless otherwise stated.

\section{RESULTS AND DISCUSSION}

Comparison of $N$. maritimus and $N$. oceani response to Fe' and $\mathrm{Cu}^{2+}$

We examined and compared the effect of unchelated $\mathrm{Fe}^{\prime}$ and $\mathrm{Cu}^{2+}$ on the growth of the ammonia-oxidising bacterium, $N$. oceani strain C-107 with that of the archaeal isolate, $N$. maritimus strain SCM1 previously published. ${ }^{21,22} \mathrm{~N}$. oceani required $0.09 \mathrm{pmol} \mathrm{L}^{-1}$ $\mathrm{Cu}^{2+}$ to reach maximum specific growth rates $\left(\mu_{\max }\right)$ of $0.61 \mathrm{~d}^{-1}$ $( \pm 0.04)$, becoming growth-limited at $<0.09 \mathrm{pmol} \mathrm{L}^{-1} \mathrm{Cu}^{2+}$ and ceasing all growth at $\leq 0.05 \mathrm{pmol} \mathrm{L}^{-1} \mathrm{Cu}^{2+}$ (Fig. 1). At $\mu_{\max }, N$. oceani cells contained $3.1 \times 10^{-19} \mathrm{~mol} \mathrm{Cu} \mathrm{cell}^{-1}\left( \pm 1.9 \times 10^{-19}\right)$, equating to a Cu:P of $0.13 \mathrm{mmol} \mathrm{mol}^{-1}$. In contrast, $N$. maritimus requires a greater $\left[\mathrm{Cu}^{2+}\right]$ to reach $\mu_{\max }\left(1 \mathrm{pmol} \mathrm{L^{-1 }} \mathrm{Cu}^{2+}\right)$ but is able to maintain growth at $<0.05 \mathrm{pmol} \mathrm{L}^{-1} \mathrm{Cu}^{2+}$. ${ }^{21}$ At $\mu_{\max }$ we found that $N$. maritimus had a greater cellular $\mathrm{Cu}$ quota of $4.9 \times$ $10^{-18} \mathrm{~mol} \mathrm{Cu} \mathrm{cell}^{-1}\left( \pm 1.9 \times 10^{-19}\right)$ compared with $N$. oceani at $\mu_{\max }$ (Mann-Whitney $U$ test). To our knowledge, $N$. maritimus has the greatest cellular Cu:P quota of $1.89 \mathrm{mmol} \mathrm{mol}^{-1}$ documented for any marine microorganism growing at $\mu_{\max }$. Maximum growth rates in $N$. oceani between 0.09 and $0.14 \mathrm{pmol} \mathrm{L}^{-1} \mathrm{Cu}^{2+}$ may appear to result from the expression of a high-affinity $\mathrm{Cu}$ uptake system in a similar mechanism to that demonstrated for Fe. ${ }^{47} \mathrm{As} N$. oceani does not possess any known genes for high-affinity $\mathrm{Cu}$ uptake (e.g. CTR or ctaA-see below for further discussion), we posit that the reduction in $\mu$ at $>0.14 \mathrm{pmol} \mathrm{L}^{-1} \mathrm{Cu}^{2+}$ is more likely a toxicity response. Our results suggest that $N$. oceani is more susceptible to $\mathrm{Cu}^{2+}$ toxicity than $N$. maritimus: at $53.54 \mathrm{pmol} \mathrm{L}^{-1}$

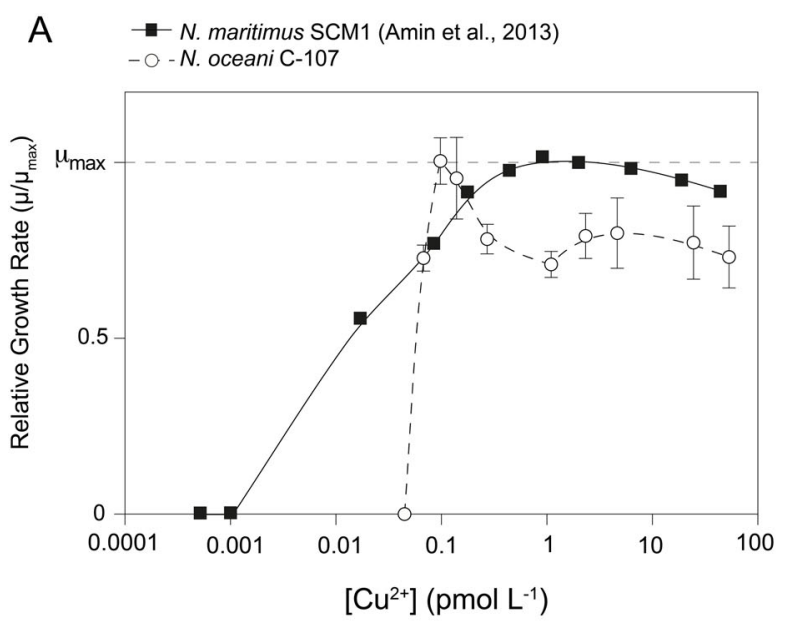

C
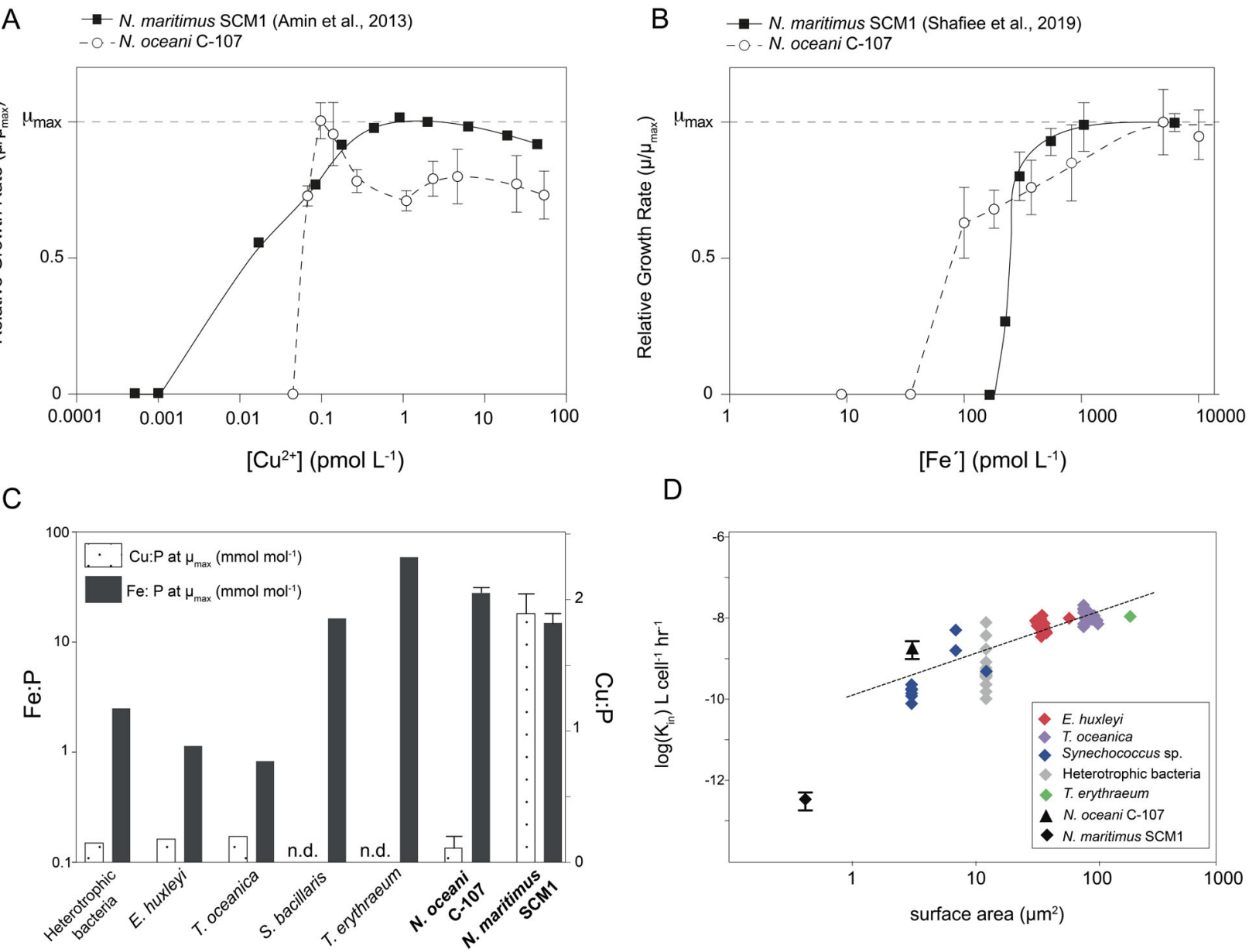

$\mathrm{D}$

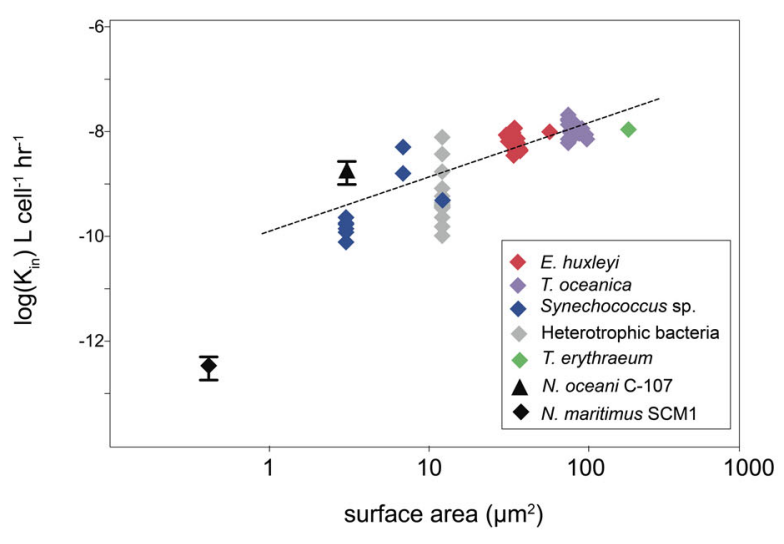

Fig. 1 Iron and copper dose-response curves, cellular quotas and steady-state uptake rates of AOA and AOB isolates, Nitrosopumilus maritimus and Nitrosococcus oceani. Effect of $(\mathbf{A})$ cupric ion concentration $\left[\mathrm{Cu}^{2+}\right]\left(\mathrm{pmol} \mathrm{L}^{-1}\right)(\mathbf{B})$ unchelated Fe concentration $\left.(\mathrm{Fe})^{\prime}\right)$ on the relative growth rate $\left(\mu / \mu_{\max }\right)$ of the ammonia-oxidising bacterium Nitrosococcus oceani strain C-107 (open circles and dashed line) compared with previously published data on the ammonia-oxidising archaeon Nitrosopumilus maritimus strain SCM1 $1^{21,22}$ (closed squares and solid black line-error bars within points on N. maritimus data). Error bars on $N$. oceani points represent standard deviation calculated on $n=21$ (three replicates were conducted for each treatment in a total of seven acclimated sub-cultures-calculated to be statistically indistinguishable, ANOVA, $P<0.01$ ). Error bars on $N$. maritimus SCM1 data points in 1B) represent standard deviation on $n=20$, as calculated previously. ${ }^{23}$ (C) Intracellular $\mathrm{Cu}$ and Fe quota in mol cell ${ }^{-1}$ normalised to mol P cell ${ }^{-1}$ at maximum relative growth rate, $\mu_{\max }$, in $N$. oceani and $N$. maritimus (Cu quota calculated in this study, Fe quota calculated in ref. ${ }^{22}$ ) compared with published quota data of numerous marine phytoplankton (data and references provided in Supplementary Table). Fe:P and Cu:P at $\mu_{\max }$ in $N$. oceani was measured at $5006 \mathrm{pmol} \mathrm{L}^{-1} \mathrm{Fe} \mathrm{e}^{\prime}$ and 0.07 pmol $\mathrm{L}^{-1} \mathrm{Cu}^{2+}$, respectively. Cu:P at $\mu_{\max }$ in $N$. maritimus SCM1 was measured at $0.97 \mathrm{pmol} \mathrm{L}{ }^{-1} \mathrm{Cu}^{2+}$. Additional Fe and Cu quota under varying [Fe'] and $\left[\mathrm{Cu}^{2+}\right]$ is provided in Table 1 and Supplementary Fig. 1. See Supplementary Materials for further discussion on the use of quota data at $\mu_{\max }$. Error bars on $N$. oceani data represent standard deviation, $n=3$. D log $K_{i n}$, Fe' steady state-uptake constant, in $\mathrm{L}_{\text {cell }}^{-1} \mathrm{~h}^{-1}$ as a function of cellular surface area $\left(\mu \mathrm{m}^{3}\right)$ in $N$. oceani (filled diamond) compared with published data of $N$. maritimus ${ }^{22}$ and other marine phytoplankton. ${ }^{48}$ Error bars represent standard deviation, $n=6$. 
$\mathrm{Cu}^{2+}, N$. oceani growth was $28 \%$ below $\mu_{\max }$ compared with $N$. maritimus growth rate that was only reduced by $10 \%$ at the equivalent $\left[\mathrm{Cu}^{2+}\right]$.

While $N$. maritimus requires an elevated $\left[\mathrm{Cu}^{2+}\right]$ to reach $\mu_{\max }$ and is able to maintain growth at lower $\left[\mathrm{Cu}^{2+}\right]$ compared with $\mathrm{N}$. oceani, we observed the opposite trend between the two microorganisms with respect to $\mathrm{Fe}^{\prime}$. $N$. oceani reached $\mu_{\max }$ at $5006 \mathrm{pmol}^{-1} \mathrm{Fe}^{\prime}$ and became partially growth limited in treatments with $\leq 828 \mathrm{pmol} \mathrm{L}^{-1}$ (Fig. 1). N. oceani growth was not detected in treatments with $<100$ pmol L ${ }^{-1} \mathrm{Fe}^{\prime}$. At $\mu_{\max }$ the intracellular Fe quota of $N$. oceani cells was $6.1 \times 10^{-17} \mathrm{~mol} \mathrm{Fe} \mathrm{cell}^{-1}\left( \pm 1.1 \times 10^{-17}\right)$. In contrast, $N$. maritimus reaches $\mu_{\max }$ at a lower [ $\left.\mathrm{Fe}^{\prime}\right]$ of $550 \mathrm{pmol} \mathrm{L}^{-1}$, and is unable to grow at $<250$ pmol L ${ }^{-1} \mathrm{Fe}^{\prime 22}$ At $\mu_{\max }, N$. maritimus cells have an intracellular Fe quota of $6.5 \times 10^{-18} \mathrm{~mol} \mathrm{Fe} \mathrm{cell}^{-1}( \pm 1.3 \times$ $10^{-18}$ ) - an order of magnitude less than intracellular Fe quota of $N$. oceani at $\mu_{\max }$ (Student's $T$-test, two-tailed, $P<0.01$ ). The $N$. oceani steady-state $\mathrm{Fe}^{\prime}$ uptake rate constant $\left(K_{i n}\right)$, an indicator of Fe affinity, is typical based on the linear relationship between $K_{\text {in }}$ and S.A. in marine phytoplankton and heterotrophic bacteria. ${ }^{48} \mathrm{~N}$. maritimus deviates from the linear relationship between $K_{\text {in }}$ and $\mathrm{S}$. A. with a lower $K_{\text {in }}$ of $4.5 \times 10^{-13} \mathrm{~L} \mathrm{cell}^{-1} \mathrm{~h}^{-1}\left( \pm 1.2 \times 10^{-13}\right)$ and therefore per unit S.A. N. maritimus has a lower $\mathrm{Fe}^{\prime}$ uptake rate compared with $N$. oceani and cosmopolitan marine microorganisms (Supplementary Fig. 7).

\section{Metal requirements and uptake strategies across $A O A$ and AOB communities}

To explore whether $\mathrm{Cu}$ and $\mathrm{Fe}$ quotas in $N$. oceani and $N$. maritimus at $\mu_{\max }$ (Fig. 1) are likely to be representative of broader $A O A$ and $A O B$ communities, we analysed the number of $\mathrm{Cu}$ - and Fe-binding sites in available marine $A O A$ and $A O B$ genomepredicted proteomes. We found that the number of hypothetical Fe-binding sites in genome-predicted proteomes were significantly greater in marine AOB compared to AOA (Fig. 2, Student's $T$-test, $P<0.0001$, Fig. 3 ). As such, it is plausible that the greater measured Fe quota at $\mu_{\max }$ in $N$. oceani is reflective of broader marine $A O A$ and $A O B$ communities, supporting the notion that a greater utilisation of cytochromes ${ }^{19,20}$ burdens $A O B$ with a significant additional Fe demand relative to AOA. The same trend is evident when normalised to proteome size $(P=0.006)$, indicating that the greater number of Fe-binding sites is not an artefact of the larger average genome size in AOB. We did not observe a significant difference between the absolute number of $\mathrm{Cu}$ - binding sites in genome-predicted proteomes of $\mathrm{AOA}$ and AOB (Fig. 2). Individually $N$. oceani and $N$. maritimus differ in the number of $\mathrm{Cu}$-binding sites per genome-33 in N. maritimus versus only 22 in $N$. oceani. Therefore, we speculate that the greater Cu quota per cell in N. maritimus compared with $N$. oceani reflects species-level differences and does not necessarily represent trends among the wider $A O A$ and $A O B$ community. However, when normalised to proteome size, AOA are enriched in $\mathrm{Cu}$-binding proteins, suggesting that greater $\mathrm{Cu}: \mathrm{P}$ in N. maritimus compared with $N$. oceani (Fig. 1) may be reflective of broader AOA and $\mathrm{AOB}$ communities. A greater Cu:P in N. maritimus compared to $A O B$ supports genome and proteome analysis revealing relative to their small proteome/genome size, AOA have an unusually high number of $\mathrm{Cu}$ proteins, including plastocyanins and multi-copper oxidases with a putative role in electron transport. ${ }^{18,49}$

\section{Inorganic Fe uptake}

The $\mathrm{Fe}^{\prime}$ uptake rate constant normalised to S.A. in N. oceani exceeds numerous marine microorganisms including $N$. maritimus (Supplementary Fig. 7), suggesting that if illustrative of wider AOB physiologies, $A O B$ may be effective competitors for $\mathrm{Fe}^{\prime}$ in the marine environment. Analyses of the trace metal uptake complement of available AOB genomes support the case for $N$. oceani C107 as a suitable representative for wider AOB physiologies: all $A O B$ in our analysis had at least one inorganic Fe-specific uptake system, compared with only $40 \%$ of AOA (Fig. 3 and Supplementary Fig. 8). The genomes of all Nitrosococcus species encode proteins for the high-affinity FTR/Fet3p Fe ${ }^{2+}$ uptake system (Fig. 3), comprising a multicopper oxidase (Fet3p) that oxidises $\mathrm{Fe}^{2+}$ to $\mathrm{Fe}^{3+}$ prior to uptake across the inner membrane by FTR. ${ }^{48}$ Given that the main Fe' substrate in EDTA-buffered systems is $\mathrm{Fe}^{3+}$, we predict that $\mathrm{Fe}^{3+}$ is reduced prior to being delivered to the FTR/Fet3p system for re-oxidation as demonstrated in previous work. ${ }^{50}$ FTR has high substrate specificity for $\mathrm{Fe}^{3+}$ which has been oxidised by the Fet $3 p$ multicopper oxidase and as such exogenous $\mathrm{Fe}^{3+}$ cannot be provided directly to FTR for uptake. ${ }^{50}$ As we did not observe any reduction in growth rate with the addition of ferrozine (FZ) (Supplementary Fig. 9), any $\mathrm{Fe}^{3+}$ reduction does likely not occur extracellularly but rather in the periplasmic space before uptake.

In contrast, $N$. maritimus does not possess any genes diagnostic of known inorganic Fe-uptake systems suggesting a reliance on general cation ZIP transporters for $\mathrm{Fe}^{2+}$ uptake or the utilisation of a hitherto uncharacterised Fe-specific transporter. A low Fe' steady-state uptake rate in $N$. maritimus (Fig. 1) points to Fe uptake by non-specific ZIP transporters rather than an uncharacterised Fe-specific transporter. N. maritimus SCM1 was isolated from a marine aquarium, ${ }^{33}$ calling into question whether the Fe uptake strategies seen in $N$. maritimus are reflective of the environmental AOA populations or whether species such as $\mathrm{Ca}$. Nitrosopelagicus brevis, ${ }^{49}$ with Fe-specific uptake transporters (Fig. 3) are in fact more typical of oceanic AOA. Previous work shows that $N$. maritimus is closely related to marine AOA (in situ and those recovered in enrichment cultures) based on gene content and sequence $7,8,18,51,52$ and meta-genomic and transcriptomic analyses point to the dominance of Thaumarchaeota belonging to 'Nitrosopumilus-type' Nitrospumilales in the oceans. ${ }^{53-55}$ In addition, Thaumarcheotal genes homologous to non-specific metal transporters in $N$. maritimus have been shown to be more prevalent in the TARA metagenomic database compared with $\mathrm{Ca}$. $N$. brevis-related Fe transporters. ${ }^{22}$ Together these results suggest that $N$. maritimus may be more representative of broader marine AOA Fe uptake dynamics; however, it is still plausible that Fe uptake strategies play into the niche separation of AOA 'ecotypes' or clades in a manner similar to $\mathrm{NH}_{4}{ }^{+}$, light and oxygen concentrations ${ }^{56-59}$ and provide interesting avenues for future research.

\section{Chelated iron uptake and siderophore biosynthesis}

Despite that fact that $A O B$ isolates appear to be more competitive for Fe' compared with AOA isolates, $\mathrm{Fe}^{\prime}$ is still exceedingly scarce in the marine environments with $>99.9 \%$ Fe complexed to organic ligands. ${ }^{60} \mathrm{~N}$. maritimus has been shown to be able to utilise Fe even when strongly chelated to the siderophore desferrioxamine $B$ mesylate (DFB), using an extracellular reductive uptake strategy, but shows no physiological and bioinformatic evidence of producing siderophores endogenously $(22$, Fig. 3$)$. An inability to produce siderophores across the Thaumarchaeota phylum is suggested by the absence of known siderophore biosynthesis genes in all AOA genomes we examined (Fig. 3; Supplementary Fig. 8). In contrast, the $N$. oceani genome encodes an aerobactin biosynthesis pathway, ${ }^{61}$ a capability likely widespread across AOB: $88 \%$ of marine AOB genomes have at least one gene diagnostic of a siderophore biosynthetic pathway (Fig. 3). We did not observe any growth of $N$. oceani in medium wherein all Fe was chelated to a xenosiderophore, desferrioxamine B (Supplementary Fig. 9). However, all but one of the AOB genomes examined encoded multiple TonB-dependent transporters and at least one periplasmic substrate-binding protein capable of transporting siderophores across the outer and inner bacterial membrane (e.g. fecCD, fhuD, fiu-see Supplementary Table for full list). The only AOA genome that encodes TonB-dependent transport is $N$. maritimus-the function of this transporter remains to be investigated given that 
N. maritimus SCM1

A

O N. oceani C-107

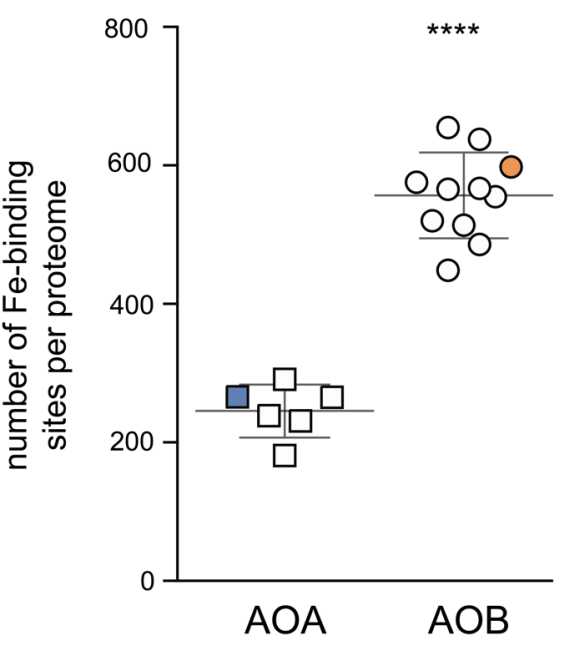

C

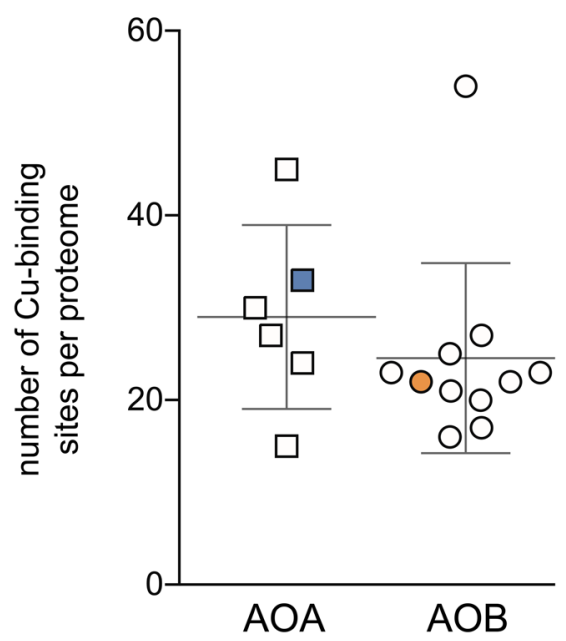

B

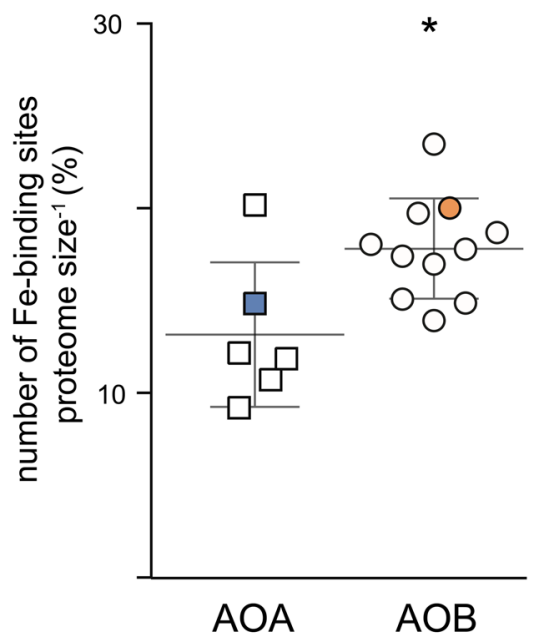

D

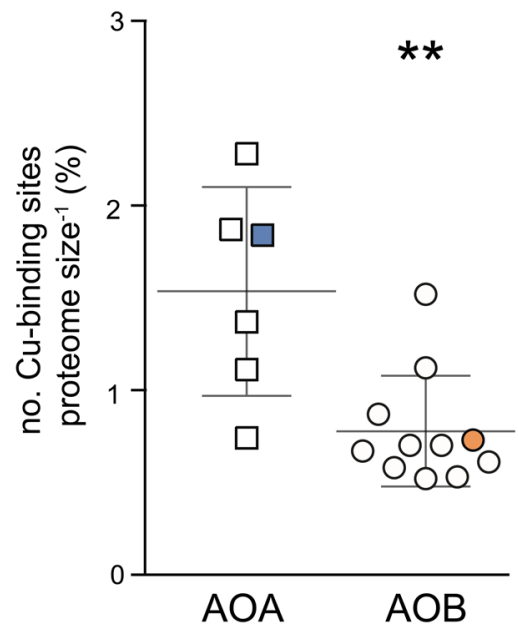

Fig. 2 Absolute and relative number of iron- and copper- binding sites in the genome-predicted proteomes of Nitrosopumilus maritimus and Nitrosococcus oceani. (A) Absolute number of Fe-binding sites per genome-predicted proteome of marine (coastal and open ocean) AOA and AOB. See Supplementary Materials for full discussion of included species. ${ }^{* * *}$ denotes that values are significantly different between AOA and AOB (Student's $T$-test, two-tailed, $P<0.0001$ ). (B) Number of Fe-binding sites annotated in the genome-predicted proteome of marine $\mathrm{AOA}$ and $\mathrm{AOB}$ relative to proteome size (number of proteins predicted from the genome) as a percentage. ${ }^{*}$ denotes that values are significantly different between AOA and AOB ( $T$ test, two-tailed, $P<0.05)$. (C) Absolute number of Cu-binding sites annotated in the genomepredicted proteome of marine (coastal and open ocean) AOA and AOB. See Supplementary Materials for full discussion of included species. (D) Number of Cu-binding sites annotated in the genome-predicted proteome of marine AOA and AOB relative to proteome size (number of proteins predicted from the genome) as a percentage. ${ }^{* *}$ denotes that values are significantly different between AOA and AOB ( $T$ test, twotailed, $P<0.01$ ). For plots $\mathbf{A}-\mathbf{D}, \mathrm{AOA} n=6, \mathrm{AOB} n=11$. Error bars indicate standard deviation and the middle line indicates mean. All data are available in Supplementary Table 1.

N. maritimus reduces Fe extracellularly. ${ }^{22}$ However, all AOB genomes that we examined (except $N$. halophilia $\mathrm{Nm}$ 1) encode multiple TonB-dependent transporters and at least one periplasmic substrate-binding protein capable of transporting siderophores across the outer and inner bacterial membrane, respectively (Fig. 3 and Supplementary Fig. 8). Addition of ferrozine (FZ) in EDTAbuffered cultures did not inhibit $N$. oceani growth rates (Supplementary Fig. 9), suggesting that $N$. oceani does not employ a reductive Fe uptake strategy and we did not find any bioinformatic evidence for extracellular ferrireductases in $N$. oceani or $A O B$ genomes. Taken together, these results suggest that $A O B$ are only able to access specific forms of Fe chelates, utilising a direct uptake strategy rather than reducing $\mathrm{Fe}^{3+}$ to $\mathrm{Fe}^{2+}$ from $\mathrm{Fe}$ chelates extracellularly as suggested for $\mathrm{N}$. maritimus. ${ }^{22}$ The ferrireductase responsible for reductive uptake in $N$. maritimus has not yet been identified and other AOA genomes do not encode typical ferrireductases (e.g. FRE or SIP), hampering efforts to explore the extent of a reductive uptake strategy among the wider AOA community. If a non-discriminate reductive uptake strategy is widespread among AOA, it may provide a key competitive advantage over $A O B$ that are constrained to specific Fe chelates and Fe' to satisfy Fe demand. Although $\mathrm{AOB}$ are able to respond to Fe scarcity by producing siderophores, siderophores are subject to diffusive losses in the marine environment ${ }^{62}$ and can be taken up 


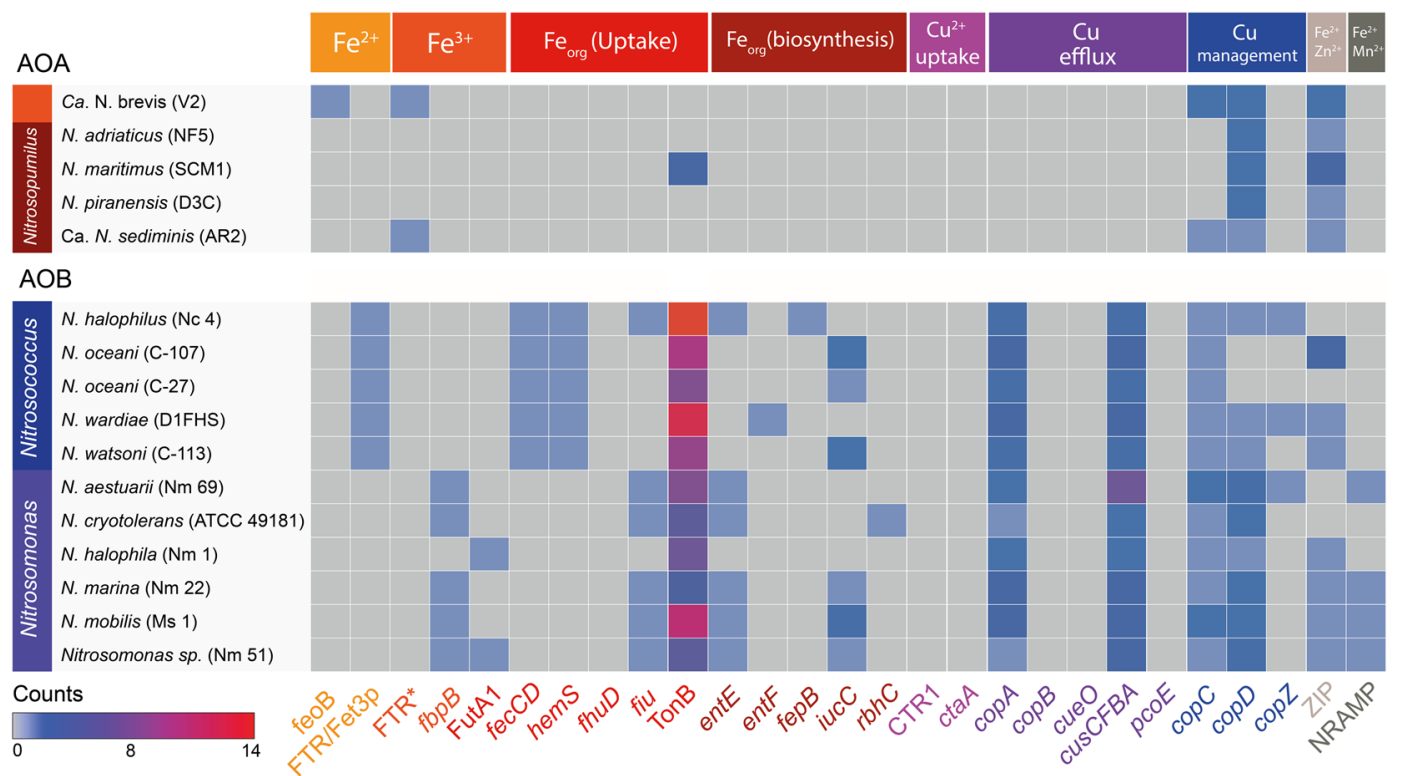

Fig. 3 Presence of genes for metal uptake systems, siderophore uptake and biosynthesis systems, and copper toxicity management systems in marine AOA and AOB genomes, with colours responding to the number of counts. Metal uptake systems are partitioned by colour based on their metal substrate. A full description of metal transport systems searched in the analysis and data are outlined in Supplementary Table 1. AOA and AOB are partitioned by genus. Strains are given in brackets alongside species names. *FTR refers to the presence of FTR1 gene only without the corresponding fet3p gene that constitutes high-affinity $\mathrm{Fe}^{3+}$ uptake.

by other 'cheating' microorganisms. In the oligotrophic ocean a 'generalist' reductive strategy as seen in $N$. maritimus, allowing access to a broader range of Fe substrates, may be a favourable strategy over the siderophore production ${ }^{63,64}$ and direct uptake of distinct Fe complexes of $N$. oceani and other AOB.

\section{Cu uptake and management}

The ability of $N$. maritimus to maintain growth under lower $\left[\mathrm{Cu}^{2+}\right]$ compared with $A O B$ points to the presence of a high-affinity $\mathrm{Cu}$ uptake system such as CTR1, yet our analysis did not reveal the presence of such systems in either of the examined AOA or AOB genomes across all environments (Supplementary Table). A higher affinity for $\mathrm{Cu}^{2+}$ in $\mathrm{N}$. maritimus has been hypothesised to be due to the chemical characteristics of their S-layer: $\mathrm{Cu}^{2+}$ is characterised as a 'soft' metal and is therefore attracted to polarisable 'soft' thiol ligands within the archaeal S-layer, accumulating $\mathrm{Cu}^{2+}$ at the cell surface to greater concentrations. ${ }^{36,65,66}$ The distinctive S-layer is common to $A O A$ and absent from $A O B$ across all environments-indicating that an ability to grow under low $\mathrm{Cu}^{2+}$ may be widespread among Thaumarchaeota. Indeed, the soil archaeon Nitrososphaera viennensis and other AOA can maintain growth in $\left[\mathrm{Cu}^{2+}\right]$ as low as $10^{-4}$ pmol $\mathrm{L}^{-1} \mathrm{Cu}^{2+67-69}$ nearly two orders of magnitude lower than $\left[\mathrm{Cu}^{2+}\right]$ needed to support $N$. maritimus growth. Previous work shows that the soil AOB, Nitrosomonas europaea, can maintain growth at $\left[\mathrm{Cu}^{2+}\right]$ below concentrations that are limiting to soil $\mathrm{AOA}^{67}$ signifying that environment-specific selection pressures may be at play and that there is likely species-specific physiological diversity within AOA and $A O B$ groups. For instance, high nutrient environments may be less likely to select for S-layer proteins that are more chemically attractive to cations, contributing to the high diversity observed in S-layer proteins. ${ }^{66}$ Compared with N. oceani, N. maritimus is able to tolerate greater $\left[\mathrm{Cu}^{2+}\right]$ before an inhibitory effect on growth is observed $\left({ }^{21}\right.$; Fig. 1). Environmental studies mirror these results, showing that elevated $\mathrm{Cu}$ in marine sediments, river sediments and soils drives a greater reduction in $A O B$ amo $A$ gene abundances compared to $A O A$ amo $A$ gene abundances. ${ }^{70-73}$ Elevated intracellular copper leads to the production of reactive oxygen species (ROS) that can cause lipid peroxidation, protein oxidation and DNA damage necessitating the production of oxidative defence mechanisms such as superoxide dismutase or catalase. While both $A O A$ and $A O B$ encode genes for superoxide dismutase, the ability to produce the hydrogen peroxidedetoxifying enzyme catalase is absent from the genomes of $\mathrm{AOA}^{73}$ suggesting this is not the mechanism conferring increased $\mathrm{Cu}^{2+}$ resistance to $\mathrm{AOA}$.

Our analysis revealed the presence of at least two known $\mathrm{Cu}$ efflux and internal $\mathrm{Cu}$ management systems in all AOB. These systems include the Cu-exporting CopA, ${ }^{74}$ and CusA ${ }^{75}$ families and the cytoplasm $\mathrm{Cu}$ chaperone $\mathrm{CopC}$ and $\mathrm{CopD}^{76}$ and $\mathrm{CopZ}^{77}$ families. In contrast, AOA genomes do not encode any $\mathrm{Cu}$ efflux proteins, and only contain $\operatorname{cop} C$ and/or $\operatorname{cop} D$ genes that play a putative role in chaperoning $\mathrm{Cu}$ within the cell. ${ }^{76}$ The rarity of $\mathrm{Cu}$ efflux systems is not unique to Thaumarchaeota: genomes across the Archaeal domain encode significantly fewer $\mathrm{Cu}$ efflux genes compared to genomes of the Bacterial domain ${ }^{78}$ calling into question the mechanism allowing $\mathrm{AOA}$ isolates to tolerate greater $\left[\mathrm{Cu}^{2+}\right]$ in culture (Fig. 1). Amin et al. ${ }^{21}$ found that under Cu-replete conditions, N. maritimus produced weak ligands that were not produced under $\mathrm{Cu}$-limiting conditions. The production of ligands with a range of stability constants, which form complexes with free $\mathrm{Cu}^{2+}$ thereby preventing it from accumulating on cell surfaces, is a common indirect strategy among marine microorganisms to manage high $\mathrm{Cu}^{2+} \cdot{ }^{79-81}$ If the ligands produced by $N$. maritimus are playing a similar role in lowering cupric ion activity, it explains how $N$. maritimus is able to tolerate higher (calculated) $\left[\mathrm{Cu}^{2+}\right]$, despite the lack of known Cu-detoxification genes in its genome.

\section{Implications for marine ammonia oxidation, niche separation} and evolution of ammonia oxidation

Copper limitation of ammonia oxidation. While 'omics approaches are useful in making initial predictions about microbial niche separation, the effect of genotypic variation on physiology is more robustly gleaned from examining pure isolates in controlled culture conditions-a non-trivial task given that pure isolates of $A O A$ and $A O B$ are lacking. If representative of in situ communities, as suggested by our bioinformatic analysis of available genomes, 
our physiological characterisation of $N$. oceani C-107 and N. maritimus SCM1 provides testable hypotheses and new avenues to be explored in future research.

To our knowledge the cupric ion concentration $\left(\left[\mathrm{Cu}^{2+}\right]\right)$ required for minimum growth in $\mathrm{N}$. oceani $\mathrm{C}-107$ and $\mathrm{N}$. maritimus SCM1, is greater than all other microbial components of the marine N-cycle, ${ }^{21,26,82-85}$ (Supplementary Table 1 and Supplementary Fig. 10) examined to date, suggesting that ammonia oxidation may act as a bottleneck in marine biogeochemical $\mathrm{N}$-cycling when $\left[\mathrm{Cu}^{2+}\right]$ is low. We hypothesise that ammonia oxidation in the Pacific Ocean may be susceptible to $\mathrm{Cu}$ limitation, as $\left[\mathrm{Cu}^{2+}\right]$ measured in the Pacific can be spatially and temporally below the $\mathrm{AOA}$ and $\mathrm{AOB} \mathrm{Cu}$-limiting threshold $\left(<0.01 \mathrm{pmol} \mathrm{L}^{-1} \mathrm{Cu}^{2+}\right)$ (Fig. 4). In the North East Pacific, where $\left[\mathrm{Cu}^{2+}\right]$ has been documented to be $<0.001 \mathrm{pmol} \mathrm{L}^{-1} \mathrm{Cu}^{2+}$ at all depths, ${ }^{86,87} \mathrm{Cu}$ limitation may extend throughout the water column, contributing to the low observed ammonia-oxidation rates and $a m o A$ gene abundances despite otherwise replete $\mathrm{NH}_{4}{ }^{+} \cdot{ }^{13} \mathrm{Cu}$-amendment experiments conducted in situ will be necessary in order to test this hypothesis as open-ocean ecotypes may harbour physiologies distinct to those demonstrated here.

The observation that $A O B$ become completely growth limited at greater $\left[\mathrm{Cu}^{2+}\right]$ relative to the AOA aligns with observations of lower AOB: $\mathrm{AOA}$ abundances under $\mathrm{Cu}$-deplete regimes in the North East Pacific $\left(0.0001-0.01\right.$ pmol L $\left.{ }^{-1} \mathrm{Cu}^{2+}\right)$, despite concentrations of $\mathrm{NH}_{4}^{+}$which are otherwise sufficient to support AOB growth. ${ }^{14}\left[\mathrm{Cu}^{2+}\right]$ ranges over five orders of magnitude between the surface and deep ocean (Fig. 4) $\left(0.0001-10 \mathrm{pmol} \mathrm{L}^{-1} \mathrm{Cu}^{2+}\right.$ ) and varies three orders of magnitude between ocean basins $\left(0.0010 \mathrm{pmol}^{-1} \mathrm{Cu}^{2+}\right.$ in the Pacific ${ }^{86,87}$ to $0.2 \mathrm{pmol} \mathrm{L}^{-1} \mathrm{Cu}^{2+}$ in the North Atlantic $\left.{ }^{88}\right)$. The ability of $N$. maritimus to support growth over a broader $\left[\mathrm{Cu}^{2+}\right]$ range, may provide an additional adaptation, in addition to a higher affinity for $\mathrm{NH}_{4}{ }^{+}{ }_{14}$ which contributes to the greater success of AOA in the environment.

$A O A$ and $A O B$ trace metal niche separation. As $A O B$ have a lower affinity for $\mathrm{NH}_{4}{ }^{+}$compared with $\mathrm{AOA},{ }^{14}$ it follows that $\mathrm{AOB}$ must occupy a niche with a high $\mathrm{NH}_{4}{ }^{+}$supply to fulfil their $\mathrm{NH}_{4}{ }^{+}$ demand. $\mathrm{NH}_{4}{ }^{+}$depth profiles show that $\mathrm{NH}_{4}{ }^{+}$begins to accumulate to appreciable levels within the photic zone between 50 and 100 m (Fig. 5), as light limitation of phytoplankton growth causes $\mathrm{NH}_{4}{ }^{+}$consumption to slow. ${ }^{89,90}$ Compiled depth profiles show that $A O B$ amoA abundances also peak below $100 \mathrm{~m}$ depth (Fig. 5 and Supplementary Fig. 11), shallower than AOA, pointing to the greater role of $\mathrm{NH}_{4}^{+}$supply in governing the vertical distribution of AOB. A need to be proximal to high $\mathrm{NH}_{4}{ }^{+}$supply in shallower waters would force $A O B$ to conform to the trace metal environment of sunlit surface waters: scarce Fe with fierce competition with phytoplankton and heterotrophic bacteria. A high affinity for Fe' demonstrated in N. oceani, and the presence of Fe-specific transporters among the wider $A O B$ community (Fig. 3), suggests that $A O B$ would be effective competitors with marine phytoplankton and bacteria for unchelated $\mathrm{Fe}$ in the photic zone. AOB would also be able to respond to chronic Fe scarcity in upper surface waters by producing their own siderophores to enhance access to Fe. A niche for $A O B$ in the sunlit upper water column is also supported by evidence indicating that $A O B$ have a higher tolerance to irradiance than AOA., ${ }^{3,91}$ At shallower depths, AOB would avoid any toxic effects of $\mathrm{Cu}^{2+}$ deeper in the water column: below $200 \mathrm{~m}$ depth $\left[\mathrm{Cu}^{2+}\right](>1$ pmol $\mathrm{L}^{-1} \mathrm{Cu}^{2+}$ ) is sufficient to cause partial inhibition of $N$. oceani growth in culture (Fig. 4). The potential for Cu toxicity is supported by observations of environmental genes and transcripts-homologous to AOB-Cu efflux proteins-which show a general scaling between $\mathrm{Cu}^{2+}$ concentration (shown in Fig. 4) and read abundance (Supplementary Figs. 12 and 13). For example, highest reads (as a percentage of total reads) are observed in the North Atlantic and North Pacific where $\mathrm{Cu}^{2+}$ can reach $0.2 \mathrm{pmol}$ $\mathrm{L}^{-1} \mathrm{Cu}^{2+}$.

In addition to explaining why $A O A$ widely outnumber $A O B$, a higher affinity for $\mathrm{NH}_{4}^{+}$compared with $A O B^{14}$ affords $A O A$ the luxury of occupying greater depths wherein the $\mathrm{NH}_{4}{ }^{+}$supply is lower, but photoinhibitory effects are substantially reduced. Indeed, AOA maxima are commonly at the base of the photic zone $^{8,11,92}$ deeper than AOB maxima (Fig. 5 and Supplementary Fig. 11). With increasing depth, competition for Fe would lessen as phytoplankton, heterotrophic bacteria and $A O B$ become limited by light, $\mathrm{DOC}^{93}$ or $\mathrm{NH}_{4}{ }^{+}$, respectively. As such, below the photic zone, there would be little selective pressure to develop a highaffinity Fe' uptake system-reflected in the rarity of inorganic Fe' transporters among marine $\mathrm{AOA}$ and the low steady-state uptake rate of $\mathrm{Fe}^{\prime}$ in $\mathrm{N}$. maritimus. As well as the reduction in competition

A N. oceani C-107

B N. maritimus SCM1

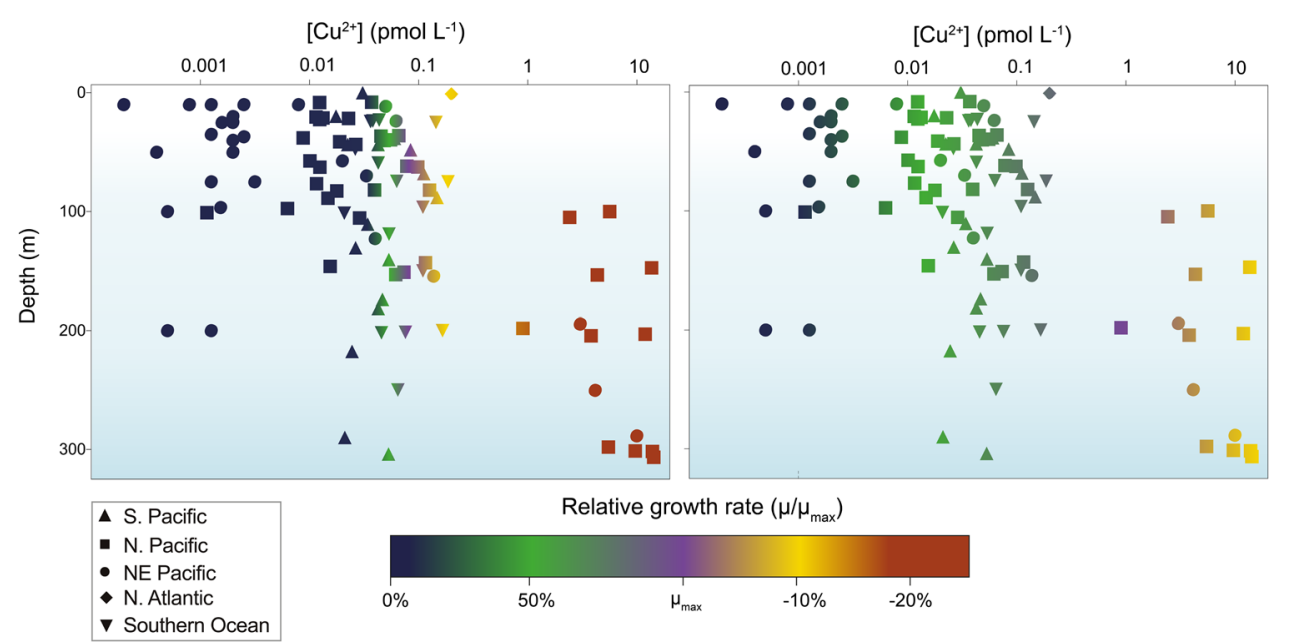

Fig. 4 Laboratory-based growth rate of the marine AOA isolate Nitrosopumilus maritimus and the AOB isolate Nitrosococcus oceani at cupric ion concentrations measured in the marine environment. Published oceanic cupric ion concentrations $\left(\left[\mathrm{Cu}^{2+}\right]\right)\left(\mathrm{see} S \mathrm{Supplementary}^{2}\right.$ Table 1 for all references) plotted against a colour gradient reflecting the relative growth rate of (A) N. oceani C-107 and (B) N. maritimus SCM1 in culture at the given $\left[\mathrm{Cu}^{2+}\right]$. For instance, at $\left[\mathrm{Cu}^{2+}\right]$ measured in the North East Pacific (on average between $0.001 \mathrm{and}^{0.01} \mathrm{pmol} \mathrm{L}^{-1} \mathrm{Cu}^{2+}$ ), no growth of $N$. oceani is observed in culture (Fig. 1), hence NE Pacific data points are largely dark blue (no growth). Growth data for $N$. oceani were obtained from this study (Fig. 1), and data for N. maritimus were previously published. ${ }^{21}$ 
A

B

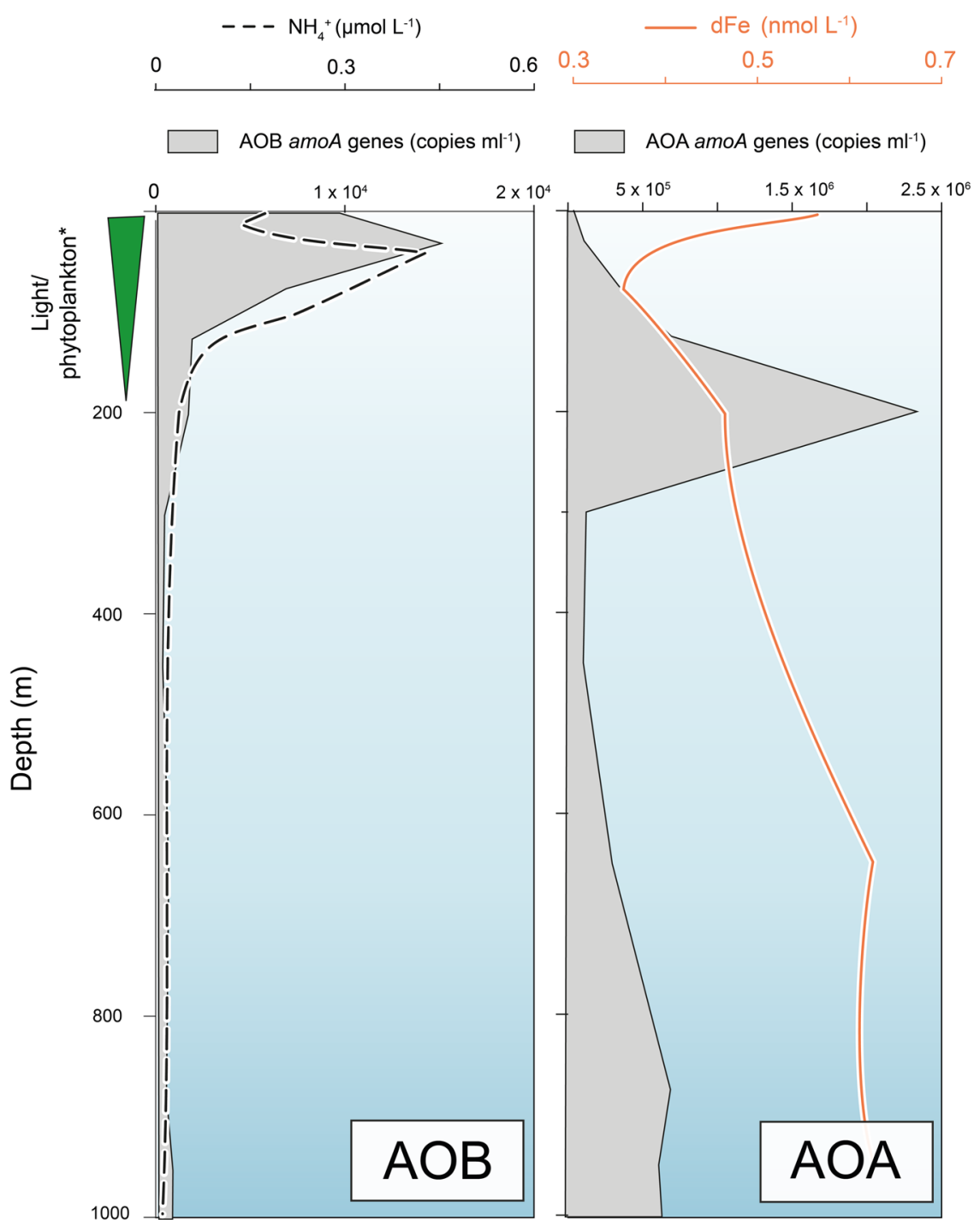

Fig. 5 Schematic showing hypothesised spatial niches of AOB and AOA. Published amoA gene abundance depth profiles (shaded grey area

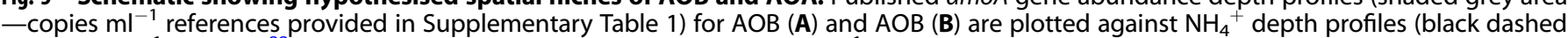
line $-\mu \mathrm{mol} \mathrm{I}^{-1}$ from ref. ${ }^{88}$ ) and dissolved Fe, dFe (orange solid line-nmol L ${ }^{-1}$, data from GEOTRACES Intermediate Data Product 2017). Green wedge labelled light/phytoplankton* reflects the relative decrease in light, phytoplankton and marine bacteria with increasing depth.

for Fe, with increasing depth, the water column becomes naturally richer in dissolved Fe as organic matter remineralises (Fig. 5). The capacity to reduce Fe chelates via a reductive strategy ${ }^{22}$ would make AOA well adapted to utilise organic Fe chelates from remineralising organic matter, which are heterogeneous in nature. ${ }^{60}$ An ecological niche driven by Fe remineralisation, which is deeper than $N$ remineralisation, potentially explains why $A O A$ abundances and nitrification rates correlate with depth-integrated primary productivity but do not respond to additions of $\mathrm{NH}_{4}{ }^{+}$in open-ocean environments. ${ }^{11,13}$

Geological implications. Molecular clock analyses constrain the timing of marine $A O A$ and $A O B$ emergence to 1084-959 million years ago (Mya) and $1169-596 \mathrm{Mya}^{94,95}$ respectively. The overlapping error of such approaches demands additional tools to constrain the emergence of archaeal and bacterial ammonia oxidisers. Consideration of evolving trace metal availabilities in the ocean over geologic time offers an approach that may complement molecular clock analyses and provide new insight into the relative timing of the emergence of $A O A$ and $A O B$. The progressive oxygenation of the oceans over geologic time has driven changes in the bioavailability of essential trace metals, notably enhancing the availability of $\mathrm{Cu}$ and $\mathrm{Zn}$ due to metal sulphide dissolution but drastically reducing the availability of $\mathrm{Fe}$, $\mathrm{Co}$ and $\mathrm{Mn}$ that are insoluble under oxic conditions. ${ }^{27,28}$ The result is a shift in microbial metal usage as organisms evolve to utilise more accessible metals, leaving imprints in the genomes, proteomes and metallomes of extant microorganisms. ${ }^{27-30,96}$ Considered in this context, a greater Fe demand and higher sensitivity to $\mathrm{Cu}$ points to an earlier emergence of the $A O B$ and additionally supports a major transition in trace metal availability between 1084 and 596 Mya driven by oxygenation ${ }^{28}$ to impart such differences in $A O A$ and $A O B$ trace metal composition. Although $A O A$ extensively outnumber $A O B$ in the modern open oceans, the greater availability of Fe may have allowed $A O B$ to play a more prominent role in the Precambrian aerobic nitrogen 
cycle. The role of oxygenation in liberating bio-essential trace metals such as $\mathrm{Cu}$ and Mo, thereby lifting limitation of certain metabolic pathways and allowing microorganisms to flourish into new trace metal niches, has previously been suggested for $\mathrm{N}_{2}$ fixation, ${ }^{97}$ but may have also influenced nitrification. A drawdown in bioavailable $\mathrm{Fe}$ and increase in $\mathrm{Cu}$ availability with oxygenation would allow AOA to proliferate into the newly available chemical niche thereby becoming the key players in the aerobic $\mathrm{N}$-cycle, owing to their lower Fe cellular quota and greater tolerance of $\mathrm{Cu}$. At this point, the contribution of $A O B$ may have been reduced due to their greater Fe demand, now scarce in a widely oxygenated ocean.

\section{CONCLUSIONS}

The results presented here provide the first parallel physiological and bioinformatic comparison of marine AOA and AOB Fe and $\mathrm{Cu}$ requirements. We hypothesise that a greater affinity for unchelated Fe allows $A O B$ to occupy shallower waters to fulfil their high $\mathrm{NH}_{4}{ }^{+}$demand, while the strategy of reducing Fe chelates would make AOA better suited to below the photic zone where Fe supply from remineralisation is greater. Further, we posit that the ability of $\mathrm{AOA}$ to tolerate a broad range of $\mathrm{Cu}$ concentrations compared with $A O B$ contributes to the global success of $A O A$ as $\mathrm{Cu}$ concentrations are highly variable in the marine environment. Considered in the context of evolving trace metal availability over geologic time, our results offer a new perspective to an ongoing debate-suggesting that the greater Fe demand but lower $\mathrm{Cu}$ tolerance of $A O B$ compared with $A O A$ is vestigial to the dominance of $A O B$ in the Precambrian when the Fe concentrations were greater but $\mathrm{Cu}$ availability was lower.

\section{REFERENCES}

1. Daims, H. et al. Complete nitrification by Nitrospira bacteria. Nature $\mathbf{5 2 8}, \mathbf{5 0 4 - 5 0 9}$ (2015).

2. Leininger, S. et al. Archaea predominate among ammonia-oxidizing prokaryotes in soils. Nature 442, 806-809 (2006).

3. Merbt, S. N., Auguet, J. C., Casamayor, E. O. \& Marti, E. Biofilm recovery in a wastewater treatment plant-influenced stream and spatial segregation of ammonia-oxidizing microbial populations. Limnol. Oceanogr. 56, 1054-1064 (2011).

4. Jiang, $H$. et al. Diversity and abundance of ammonia-oxidizing archaea and bacteria in Qinghai Lake, Northwestern China. Geomicrobiol. J. 26, 199-211 (2009).

5. Auguet, J. C., Nomokonova, N., Camarero, L. \& Casamayor, E. O. Seasonal changes of freshwater ammonia-oxidizing archaeal assemblages and nitrogen species in oligotrophic alpine lakes. Appl. Environ. Microbiol. 77, 1937-1945 (2011).

6. Mincer, T. J. et al. Quantitative distribution of presumptive archaeal and bacterial nitrifiers in Monterey Bay and the North Pacific Subtropical Gyre. Environ. Microbiol. 9, 1162-1175 (2007).

7. Wuchter, C. et al. Archaeal nitrification in the ocean. Proc. Natl Acad. Sci. USA 103, 12317-12322 (2006)

8. Santoro, A. E., Casciotti, K. L. \& Francis, C. A. Activity, abundance and diversity of nitrifying archaea and bacteria in the central California Current. Environ. Microbiol. 12, 1989-2006 (2010).

9. Santoro, A. E. et al. Measurements of nitrite production in and around the primary nitrite maximum in the central California Current. Biogeosciences 10, 7395-7410 (2013).

10. Horak, R. E. et al. Ammonia oxidation kinetics and temperature sensitivity of a natural marine community dominated by Archaea. ISME J. 7, 2023-2033 (2013).

11. Newell, S. E., Fawcett, S. E. \& Ward, B. B. Depth distribution of ammonia oxidation rates and ammonia-oxidizer community composition in the Sargasso Sea. Limnol. Oceanogr. 58, 1491-1500 (2013).

12. Peng, $X$. et al. Revisiting nitrification in the Eastern Tropical South Pacific: a focus on controls. J. Geophys. Res. Oceans. 121, 1667-1684 (2016).

13. Shiozaki, T. et al. Nitrification and its influence on biogeochemical cycles from the equatorial Pacific to the Arctic Ocean. ISME J. 10, 2184-2197 (2016).

14. Martens-Habbena, W., Berube, P. M., Urakawa, H., José, R. \& Stahl, D. A. Ammonia oxidation kinetics determine niche separation of nitrifying archaea and bacteria. Nature 461, 976-979 (2009).
15. Abell, G. C. et al. Archaeal ammonia oxidizers and nirS-type denitrifiers dominate sediment nitrifying and denitrifying populations in a subtropical macrotidal estuary. ISME J. 4, 286-300 (2010).

16. Bernhard, A. E. et al. Abundance of ammonia-oxidizing archaea and bacteria along an estuarine salinity gradient in relation to potential nitrification rates. Appl. Environ. Microbiol. 76, 1285-1289 (2010).

17. Urakawa, $\mathrm{H}$. et al. Ammonia availability shapes the seasonal distribution and activity of archaeal and bacterial ammonia oxidizers in the Puget Sound Estuary. Limnol Oceanogr 59, 1321-1335 (2014).

18. Walker, C. B. et al. Nitrosopumilus maritimus genome reveals unique mechanisms for nitrification and autotrophy in globally distributed marine crenarchaea. Proc. Natl Acad. Sci. USA 107, 8818-8823 (2010).

19. Blainey, P. C., Mosier, A. C., Potanina, A., Francis, C. A. \& Quake, S. R. Genome of a low-salinity ammonia-oxidizing archaeon determined by single-cell and metagenomic analysis. PLOS ONE 6, e16626 (2011).

20. Zannoni, D. (ed.) Respiration in Archaea and Bacteria (Kluwer Academic, 2004).

21. Amin, S. A. et al. Copper requirements of the ammonia-oxidizing archaeon Nitrosopumilus maritimus SCM1 and implications for nitrification in the marine environment. Limnol. Oceanogr. 58, 2037-2045 (2013).

22. Shafiee, R. T., Snow, J. T., Zhang, Q. \& Rickaby, R. E. M. Iron requirements and uptake strategies of the globally abundant marine ammonia-oxidising archaeon Nitrosopumilus maritimus SCM1. ISME J. 13, 2295-2305 (2019).

23. Moore, C. M. et al. Large-scale distribution of Atlantic nitrogen fixation controlled by iron availability. Nat Geosci. 2, 867-871 (2009).

24. Richier, S. et al. Abundances of iron-binding photosynthetic and nitrogen-fixing proteins of Trichodesmium both in culture and in situ from the North Atlantic. PLOS ONE 7, e35571 (2017).

25. Timmermans, K. R., Stolte, W. \& De Baar, H. J. Iron-mediated effects on nitrate reductase in marine phytoplankton. Marine Biol. 121, 389-396 (1994).

26. Granger, J. \& Ward, B. B. Accumulation of nitrogen oxides in copper-limited cultures of denitrifying bacteria. Limnol. Oceanogr. 48, 313-318 (2003).

27. Da Silva, J. F. \& Williams, R. J. The Biological Chemistry of the Elements: the Inorganic Chemistry of Life (Oxford University Press, 2001).

28. Saito, M. A., Sigman, D. M. \& Morel, F. M. The bioinorganic chemistry of the ancient ocean: the co-evolution of cyanobacterial metal requirements and biogeochemical cycles at the Archean-Proterozoic boundary? Inorganica Chim. Acta 356, 308-318 (2003)

29. Dupont, C. L., Yang, S., Palenik, B. \& Bourne, P. E. Modern proteomes contain putative imprints of ancient shifts in trace metal geochemistry. Proc. Natl Acad. Sci. USA 103, 17822-17827 (2006).

30. Williams, R. J. \& Rickaby, R. E. M. Evolution's Destiny: Co-evolving Chemistry of the Environment and Life (Royal Society of Chemistry, 2012).

31. Ward, B. B. \& O'Mullan, G. D. Worldwide distribution of Nitrosococcus oceani, a marine ammonia-oxidizing $Y$-proteobacterium, detected by PCR and sequencing of 16S rRNA and amoA genes. Appl. Environ. Microbiol. 68, 4153-4157 (2002).

32. Wang, L., Lim, C. K. \& Klotz, M. G. High synteny and sequence identity between genomes of Nitrosococcus oceani strains isolated from different oceanic gyres reveals genome economization and autochthonous clonal evolution. Microorganisms 8, 693 (2020).

33. Könneke, $M$. et al. Isolation of an autotrophic ammonia-oxidizing marine archaeon. Nature 437, 543-546 (2005).

34. Price, N. M. et al. Preparation and chemistry of the artificial algal culture medium Aquil. Biol. Oceanogr. 6, 443-461 (1989).

35. Hozuki, T. et al. Effect of salinity on hydroxylamine oxidation in a marine ammonia-oxidizing gammaproteobacterium, Nitrosococcus oceani strain NS58: molecular and catalytic properties of tetraheme cytochrome c-554. Microb. Environ. 25, 95-102 (2009).

36. Gorman-Lewis, D., Martens-Habbena, W., Stahl, D. A. \& Cu, I. I. adsorption onto ammonia-oxidizing bacteria and archaea. Geochim. Cosmochim. Acta 255, 127-143 (2019)

37. Gustafsson, J. P. Visual MINTEQ ver. 3.0; http://www2.Iwr.kth.se/English/ OurSoftware/vminteq/index.htm. (2010).

38. Zhang, Q. et al. Direct measurement of multi-elements in high matrix samples with a flow injection ICP-MS: application to the extended Emiliania huxleyi Redfield ratio. J. Anal. At. Spectrom. 33, 1196-1208 (2018).

39. Lehtovirta-Morley, L. E., Stoecker, K., Vilcinskas, A., Prosser, J. I. \& Nicol, G. W. Cultivation of an obligate acidophilic ammonia oxidizer from a nitrifying acid soil. Proc. Natl Acad. Sci. USA 108, 15892-15897 (2011).

40. Powell, S. J. \& Prosser, J. I. Inhibition of biofilm populations of Nitrosomonas europaea. Microb. Ecol. 24, 43-50 (1992).

41. Griess, P. Griess reagent: a solution of sulphanilic acid and a-naphthylamine in acetic acid which gives a pink colour on reaction with the solution obtained after decomposition of nitrosyl complexes. Chem. Ber. 12, 427 (1879).

42. Shaked, Y., Kustka, A. B. \& Morel, F. M. A general kinetic model for iron acquisition by eukaryotic phytoplankton. Limnol. Oceanogr. 50, 872-882 (2005). 
43. Kelley, L. A., Mezulis, S., Yates, C. M., Wass, M. N. \& Sternberg, M. J. The Phyre2 web portal for protein modeling, prediction and analysis. Nat. Protoc. 10, 845-858 (2015).

44. Putignano, V., Rosato, A., Banci, L. \& Andreini, C. MetalPDB in 2018: a database of metal sites in biological macromolecular structures. Nucleic Acids Res. 46, 459-464 (2018).

45. Hogle, S. L., Thrash, J. C., Dupont, C. L. \& Barbeau, K. A. Trace metal acquisition by marine heterotrophic bacterioplankton with contrasting trophic strategies. Appl. Environ. Microbiol. 82, 1613-1624 (2016).

46. Marchler-Bauer, A. et al. CDD: NCBI's conserved domain database. Nucleic Acids Res. 43, D222-D226 (2015).

47. Wilhelm, S. W. \& Trick, C. G. Iron-limited growth of cyanobacteria: multiple siderophore production is a common response. Limnol. Oceanogr. 39, 1979-1984 (1994).

48. Lis, H., Shaked, Y., Kranzler, C., Keren, N. \& Morel, F. M. Iron bioavailability to phytoplankton: an empirical approach. ISME J. 9, 1003-1013 (2015).

49. Santoro, A. E. et al. Genomic and proteomic characterization of Candidatus Nitrosopelagicus brevis: an ammonia-oxidizing archaeon from the open ocean. Proc. Natl Acad. Sci. USA 112, 1173-1178 (2015).

50. Kwok, E. \& Kosman, D. Iron in yeast: mechanisms involved in homeostasis. in Tamás, M. J. \& Martinoia, E. (Eds) Molecular Biology of Metal Homeostasis and Detoxification. (Springer, 2005). p. 1-32.

51. Agogué, H., Brink, M., Dinasquet, J. \& Herndl, G. J. Major gradients in putatively nitrifying and non-nitrifying Archaea in the deep North Atlantic. Nature 456 788-791 (2008)

52. Santoro, A. E. \& Casciotti, K. L. Enrichment and characterization of ammoniaoxidizing archaea from the open ocean: phylogeny, physiology and stable isotope fractionation. ISME J. 5, 1796-1808 (2011).

53. Reji, L., Tolar, B. B., Smith, J. M., Chavez, F. P. \& Francis, C. A. Differential cooccurrence relationships shaping ecotype diversification within Thaumarchaeota populations in the coastal ocean water column. ISME J. 13, 1144-1158 (2019).

54. King, G. M., Smith, C., Tolar, B. \& Hollibaugh, J. T. Analysis of composition and structure of coastal to mesopelagic bacterioplankton communities in the northern Gulf of Mexico. Front. Microbiol. 3, 438 (2013)

55. Stewart, F. J., Ulloa, O. \& DeLong, E. F. Microbial metatranscriptomics in a permanent marine oxygen minimum zone. Environ. Microbiol. 14, 23-40 (2012).

56. Sintes, E., De Corte, D., Ouillon, N. \& Herndl, G. J. Macroecological patterns of archaeal ammonia oxidizers in the Atlantic Ocean. Mol. Ecol. 24, 4931-4942 (2015).

57. Francis, C. A., Roberts, K. J., Beman, J. M., Santoro, A. E. \& Oakley, B. B. Ubiquity and diversity of ammonia-oxidizing archaea in water columns and sediments of the ocean. Proc. Natl Acad. Sci. USA 102, 14683-14688 (2005).

58. Luo, $\mathrm{H}$. et al. Single-cell genomics shedding light on marine Thaumarchaeota diversification. ISME J. 8, 732-736 (2014).

59. Qin, W. et al. Influence of oxygen availability on the activities of ammonia-oxidizing archaea. Environ. Microbiol. Rep. 9, 250-256 (2017).

60. Gledhill, M. \& Buck, K. N. The organic complexation of iron in the marine environment: a review. Front. Microbiol. 3, 69 (2012).

61. Klotz, M. G. et al. Complete genome sequence of the marine, chemolithoautotrophic, ammonia-oxidizing bacterium Nitrosococcus oceani ATCC 19707. Appl. Environ. Microbiol. 72, 6299-6315 (2006).

62. Völker, C. \& Wolf-Gladrow, D. A. Physical limits on iron uptake mediated by siderophores or surface reductases. Mar. Chem. 65, 227-244 (1999).

63. Kranzler, C., Lis, H., Shaked, Y. \& Keren, N. The role of reduction in iron uptake processes in a unicellular, planktonic cyanobacterium. Environ. Microbiol. 13, 2990-2999 (2011).

64. Blaby-Haas, C. E. \& Merchant, S. S. The ins and outs of algal metal transport Biochim. Biophys. Acta. 1823, 1531-1552 (2012).

65. Gorman-Lewis, D., Martens-Habbena, W. \& Stahl, D. A. Thermodynamic characterization of proton-ionizable functional groups on the cell surfaces of ammonia-oxidizing bacteria and archaea. Geobiology 12, 157-171 (2014).

66. Li, P. N. et al. Nutrient transport suggests an evolutionary basis for charged archaeal surface layer proteins. ISME J. 12, 2389-2402 (2018).

67. Gwak, J. H. et al. Archaeal nitrification is constrained by copper complexation with organic matter in municipal wastewater treatment plants. ISME J. 14, 335-346 (2020)

68. Reyes, C. et al. Genome wide transcriptomic analysis of the soil ammonia oxidizing archaeon Nitrososphaera viennensis upon exposure to copper limitation. ISME J. 14, 2659-2674 (2020).

69. Kerou, M. et al. Proteomics and comparative genomics of Nitrososphaera viennensis reveal the core genome and adaptations of archaeal ammonia oxidizers. Proc. Natl Acad. Sci. USA 113, E7937-E7946 (2016).

70. $\mathrm{Li}, \mathrm{X}$. et al. Do ammonia-oxidizing archaea respond to soil $\mathrm{Cu}$ contamination similarly as ammonia-oxidizing bacteria? Plant Soil 324, 209-217 (2009).
71. Besaury, L., Ghiglione, J. F. \& Quillet, L. Abundance, activity, and diversity of archaeal and bacterial communities in both uncontaminated and highly coppercontaminated marine sediments. Mar. biotechnol. 16, 230-242 (2014).

72. Mertens, J., Wakelin, S. A., Broos, K., McLaughlin, M. J. \& Smolders, E. Extent of copper tolerance and consequences for functional stability of the ammoniaoxidizing community in long-term copper-contaminated soils. Environ. Toxicol. Chem. 29, 27-37 (2010).

73. Kim, J. G. et al. Hydrogen peroxide detoxification is a key mechanism for growth of ammonia-oxidizing archaea. Proc. Natl Acad. Sci. USA 113, 7888-7893 (2016).

74. Odermatt, A., Krapf, R. \& Solioz, M. Induction of the putative copper ATPases, CopA and $\mathrm{CopB}$, of Enterococcus hirae by $\mathrm{Ag}+$ and $\mathrm{Cu} 2+$, and $\mathrm{Ag}+$ extrusion by CopB. Biochem. Biophys. Res. Commun. 202, 44-48 (1994).

75. Outten, F. W., Huffman, D. L., Hale, J. A. \& O'Halloran, T. V. The independent cue and cusSystems confer copper tolerance during aerobic and anaerobic growth in Escherichia coli. J. Biol. 276, 30670-30677 (2001).

76. Lawton, T. J., Kenney, G. E., Hurley, J. D. \& Rosenzweig, A. C. The CopC family: structural and bioinformatic insights into a diverse group of periplasmic copper binding proteins. Biochemisty 55, 2278-2290 (2016).

77. Solioz, M. \& Odermatt, A. Copper and silver transport by CopB-ATPase in membrane vesicles of Enterococcus hirae. J. Biol. Chem. 270, 9217-9221 (1995).

78. Ridge, P. G., Zhang, Y. \& Gladyshev, V. N. Comparative genomic analyses of copper transporters and cuproproteomes reveal evolutionary dynamics of copper utilization and its link to oxygen. PLOS ONE 3, e1378 (2008).

79. Azenha, M., Vasconcelos, M. T. \& Cabral, J. P. Organic ligands reduce copper toxicity in Pseudomonas syringae. Environ. Toxicol. Chem. 14, 369-373 (1995).

80. Croot, P. L., Moffett, J. W. \& Brand, L. E. Production of extracellular Cu complexing ligands by eucaryotic phytoplankton in response to Cu stress. Limnol. Oceanogr. 45, 619-627 (2000)

81. Moffett, J. W. \& Brand, L. E. Production of strong, extracellular Cu chelators by marine cyanobacteria in response to Cu stress. Limnol. Oceanogr. 41, 388-395 (1996).

82. Lopez, J. S., Lee, L. \& Mackey, K. R. The toxicity of copper to Crocosphaera watsonii and other marine phytoplankton: a systematic review. Front. Mar. Sci. 5, 511 (2019).

83. Brand, L. E., Sunda, W. G. \& Guillard, R. R. Reduction of marine phytoplankton reproduction rates by copper and cadmium. J. Exp. Mar. Biol. Ecol. 96, 225-250 (1986).

84. Kim, J. W. \& Price, N. M. The influence of light on copper-limited growth of an oceanic diatom, Thalassiosira oceanica (Coscinodiscophyceae). J. Phycol. 53, 938-950 (2017).

85. Sunda, W. G. \& Huntsman, S. A. Regulation of copper concentration in the oceanic nutricline by phytoplankton uptake and regeneration cycles. Limnol. Oceanogr. 40, 132-137 (1995)

86. Coale, K. H. \& Bruland, K. W. Copper complexation in the Northeast Pacific. Limnol. Oceanogr. 33, 1084-1101 (1988).

87. Whitby, H., Posacka, A. M., Maldonado, M. T. \& van den Berg, C. M. Copperbinding ligands in the NE Pacific. Mar. Chem. 204, 36-48 (2018).

88. Heller, M. I. \& Croot, P. L. Copper speciation and distribution in the Atlantic sector of the Southern Ocean. Mar. Chem. 173, 253-268 (2015).

89. Gruber, N. The marine nitrogen cycle: overview and challenges. Nitrogen Mar. Environ. 2, 1-50 (2008).

90. Diaz, F. \& Raimbault, P. Nitrogen regeneration and dissolved organic nitrogen release during spring in a NW Mediterranean coastal zone (Gulf of Lions) implications for the estimation of new production. Mar. Ecol. Prog. Ser. 197, 51-65 (2000).

91. French, E., Kozlowski, J. A., Mukherjee, M., Bullerjahn, G. \& Bollmann, A. Ecophysiological characterization of ammonia-oxidizing archaea and bacteria from freshwater. Appl. Environ. Microbiol. 78, 5773-5780 (2012).

92. Santoro, A. E. et al. Thaumarchaeal ecotype distributions across the equatorial Pacific Ocean and their potential roles in nitrification and sinking flux attenuation. Limnol. Oceanogr. 62, 1984-2003 (2017).

93. Kirchman, D. L., Keil, R. G. \& Wheeler, P. A. Carbon limitation of ammonium uptake by heterotrophic bacteria in the subarctic Pacific. Limnol. Oceanogr. 35, 1258-1266 (1990).

94. Ward, L. M., Johnston, D. T. \& Shih, P. M. Phanerozoic radiation of ammonia oxidizing bacteria. Sci. Rep. 11, 2070 (2021).

95. Ren, M. et al. Phylogenomics suggests oxygen availability as a driving force in Thaumarchaeota evolution. ISME J. 13, 2150-2161 (2019).

96. Zerkle, A. L., House, C. H. \& Brantley, S. L. Biogeochemical signatures through time as inferred from whole microbial genomes. Am. J. Sci. 305, 467-502 (2005).

97. Anbar, A. D. \& Knoll, A. H. Proterozoic ocean chemistry and evolution: a bioinorganic bridge? Science. 297, 1137-1142 (2002). 
12

\section{ACKNOWLEDGEMENTS}

We thank Phillip Holdship (Oxford) for ICP-MS technical assistance and Errin Johnson (Oxford) for assistance with SEM preparation and analysis. We also extend our gratitude to Christopher L. Dupont for comments, which greatly improved the paper. This research was supported by funding from the UK Natural Environmental Research Council (NERC) and ERC Consolidator Grant APPELS: ERC-2015-COG-681746. We also acknowledge the Royal Society for a Wolfson Research Merit Award to R.R.

\section{COMPETING INTERESTS}

The authors declare no competing interests.

\section{ADDITIONAL INFORMATION}

Supplementary information The online version contains supplementary material available at https://doi.org/10.1038/s43705-021-00001-7.

Correspondence and requests for materials should be addressed to R.T.S.
Reprints and permission information is available at http://www.nature.com/ reprints

Publisher's note Springer Nature remains neutral with regard to jurisdictional claims in published maps and institutional affiliations.

Open Access This article is licensed under a Creative Commons Attribution 4.0 International License, which permits use, sharing, adaptation, distribution and reproduction in any medium or format, as long as you give appropriate credit to the original author(s) and the source, provide a link to the Creative Commons license, and indicate if changes were made. The images or other third party material in this article are included in the article's Creative Commons license, unless indicated otherwise in a credit line to the material. If material is not included in the article's Creative Commons license and your intended use is not permitted by statutory regulation or exceeds the permitted use, you will need to obtain permission directly from the copyright holder. To view a copy of this license, visit http://creativecommons. org/licenses/by/4.0/. 